VANESSA COSTA MARUI

Eficácia de enxaguatórios bucais pré-procedimento na redução de microrganismos no aerossol: uma revisão sistemática

São Paulo

2018 

VANESSA COSTA MARUI

\section{Eficácia de enxaguatórios bucais pré-procedimento na redução de microrganismos no aerossol: uma revisão sistemática}

\section{Versão Corrigida}

Dissertação apresentada à Faculdade de Odontologia da Universidade de São Paulo, pelo Programa de Pós-Graduação em Ciências Odontológicas para obter o título de Mestre em Ciências.

Área de concentração: Periodontia

Orientador: Prof. Dr. Cláudio Mendes Pannuti 
Autorizo a reprodução e divulgação total ou parcial deste trabalho, por qualquer meio convencional ou eletrônico, para fins de estudo e pesquisa, desde que citada a fonte.

Catalogação-na-Publicação

Serviço de Documentação Odontológica

Faculdade de Odontologia da Universidade de São Paulo

Marui, Vanessa Costa.

Eficácia de enxaguatórios bucais pré-procedimento na redução de microrganismos no aerossol: uma revisão sistemática. / Vanessa Costa Marui ; orientador Cláudio Mendes Pannuti. -- São Paulo, 2018.

70p. : fig., tab.; $30 \mathrm{~cm}$.

Dissertação (mestrado) -- Programa de Pós-Graduação em Ciências Odontológicas. Área de Concentração: Periodontia. -- Faculdade de Odontologia da Universidade de São Paulo.

Versão corrigida

1. Antissépticos bucais. 2. Aerossol. 3. Consultório odontológico. I. Marui, Vanessa Costa. II. Título. 
Marui CV. Eficácia de enxaguatórios bucais pré-procedimento na redução de microrganismos no aerossol: uma revisão sistemática. Dissertação apresentada à Faculdade de Odontologia da Universidade de São Paulo para obtenção do título de Mestre em Ciências.

Aprovado em:07/12/2018

\section{Banca Examinadora}

Prof(a). Dr(a). Cristina Cunha Villar

Instituição: Universidade de São Paulo Julgamento: Aprovada

Prof(a). Dr(a). Tatiana de Carvalho Guarnieri

Instituição: Externo

Julgamento: Aprovada

Prof(a). Dr(a). José Roberto Cortelli

Instituição: Externo

Julgamento: Aprovada 

Dedico esse trabalho a todas as pessoas que amo 



\section{AGRADECIMENTOS}

Gostaria de agradecer a todos que estiveram envolvidos de maneira direta e indireta na conclusão desse trabalho.

Ao meu amado esposo Victor Alex Fernandes, por todo amor e dedicação.

Dividir uma vida com você me faz mais forte e feliz. Obrigada por todo o seu amor.

Ao meu querido orientador Prof. Dr Claudio Mendes Pannuti por toda a sabedoria, paciência e dedicação ao longo de todo o meu percurso na graduação e pós-graduação.

Ao meu pai João Marui por me dar a vida e chance de ser alguém melhor. Espero que mesmo distante você possa sentir orgulho da pessoa que me tornei.

A minha irmã Dayenne Barbosa Valêcia pela dedicação de uma vida, por todos os sorrisos e lágrimas compartilhados.

A minha afilhada Lorena Barbosa Pierre Valência por ser essa menina doce, linda e de bom coração que traz sempre mais alegria aos meus dias.

As minhas irmãs de coração Carla Berbel Chinarelli e Vivian Nunes Scudeler por todo o amor, por todas as noites de estudo, por todas as risadas e conselhos. Vocês foram um dos tesouros que a USP me deu. 
Aos meninos do meu coração: Caio Colombini, Renan Berbel, Fernando Castanheira, Renan Ito, Enoch Kim e Jun Ho Kim por toda a amizade.

Ao meu grande amigo Bruno N França por todo o apoio e carinho ao longo de todos esses anos de amizade.

A minha querida amiga Dra.Tatiana Guarnieri por toda paciência, ensinamento profissional e conselhos de vida. Eu sempre afirmo que você é uma pessoa incrível.

A Universidade de São Paulo por ser minha segunda casa e por me dar tantas oportunidades.

A todos os professores envolvidos na minha formação. 
"Seja você quem for, seja qual for a posição social que você tenha na vida, a mais alta ou a mais baixa, tenha sempre como meta muita força, muita determinação e sempre faça tudo com muito amor e com muita fé em Deus, que um dia você chega lá. De alguma maneira você chega lá".

Ayrton Senna 



\section{RESUMO}

Marui VC. Eficácia de enxaguatórios bucais pré-procedimento na redução de microrganismos no aerossol: uma revisão sistemática [dissertação]. São Paulo: Universidade de São Paulo, Faculdade de Odontologia; 2018. Versão Corrigida.

Esta revisão teve como objetivo avaliar a eficácia do uso de enxaguatórios bucais pré-procedimento na redução do número de microrganismos disseminados pelo aerossol gerado pelos procedimentos odontológicos. Apenas ensaios clínicos randomizados (ECRs) foram incluídos. As bases de dados MEDLINE (PubMed), Google Acadêmico e LILACS foram pesquisadas para busca de artigos publicados até março de 2018. Foi realizada meta-análise de efeitos aleatórios da redução de unidades formadoras de colônia (UFCs) isoladas após realização de procedimentos odontológicos que geram aerossol. Dos 725 artigos potencialmente relevantes, 12 ECRs que estudaram a eficácia da clorexidina, óleos essenciais, cloreto de cetilpiridínio e produtos fitoterápicos foram incluídos. Todos os estudos mostraram que o enxaguatório bucal pré-procedimento promoveu redução significativa no número de UFCs. A Meta-análise mostrou que enxaguatórios bucais com óleos essenciais promoveram redução percentual média de $73,9 \%$ no número de UFCs. Nenhum dos estudos incluídos apresentou baixo risco de viés. Os resultados desta revisão permitem concluir que a realização de enxágue pré-procedimento reduz significativamente o número de microrganismos noaerossol.

Palavras-chave: Antisséptico Bucal. Aerossóis. Consultórios Odontológicos. Revisão. 



\begin{abstract}
Marui VC. Efficacy of mouthwashes pre-procedural in the reduction of microorganisms in the aerosol: a systematic review. [dissertação]. São Paulo: Universidade de São Paulo, Faculdade de Odontologia; 2018. Versão Corrigida.
\end{abstract}

This review aimed to evaluate the efficacy of pre-procedural mouthrinses in reducing the number of microorganisms disseminated by the aerosol generated by dental procedures when compared to placebo or no mouthrinse. Only randomized clinical trials (RCTs) were included. MEDLINE (PubMed), Google Scholar and LILACS databases were searched for articles published until March 2018. Random effects meta-analysis was performed for reduction of the number of colony forming units (CFU) disseminated in the dental office by the aerosol. Of 725 potentially relevant articles, 12 RCTs that studied the efficacy of chlorhexidine, essential oils, cetylpyridinium chloride and herbal products were included. All studies have shown that pre-procedural mouthwashes promoted significant reduction in the number of CFUs. Meta-analysis showed that mouthwashes with essential oils promoted mean percentage reduction of $73.9 \%$ in the number of CFUs. None of the included studies presented low risk of bias. In conclusion, pre-procedural mouthwashes significantly reduce the number of microorganisms in the aerosol.

Keywords: Mouthwashes. Aerosols. Dental Offices. Review. 



\section{LISTA DE FIGURAS}

Figura 5.1 - Diagrama de seleção dos estudos. ........................................41

Figura 5.2 - Risco de viés dos estudos incluídos. ................................... 48

Figura 5.3 - Forest plot de redução percentual de unidades formadoras de

colônia............................................................................... 55 



\section{LISTA DE ABREVIATURAS E SIGLAS}

$\begin{array}{ll}\text { CHX } & \text { Clorexidina } \\ \text { CPC } & \text { Cloreto de cetilpiridínio } \\ \text { ECR } & \text { Ensaio clínico randomizado } \\ \text { OE } & \text { Óleos essenciais } \\ \text { TSA } & \text { Placas de ágar soja }\end{array}$




\section{SUMÁRIO}

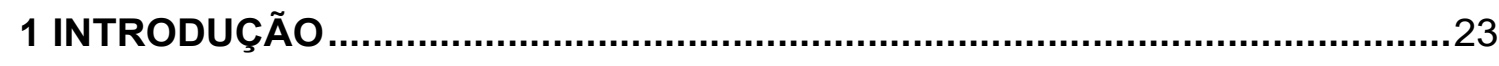

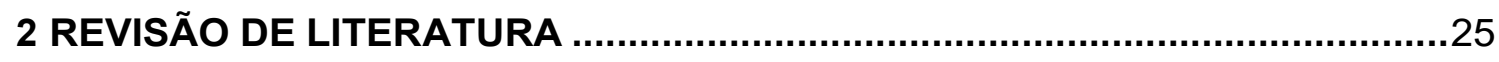

2.1 INFECÇÃO CRUZADA E O RISCO DE TRANSMISSÃO DE DOENÇAS .........25

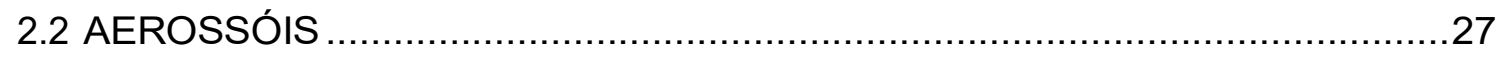

2.3 METODOS DE CONTROLE OU PREVENÇÃO DE INFECÇÃO CRUZADA .....27

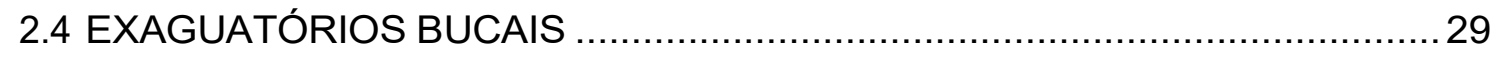

3 PROPOSIÇÃO

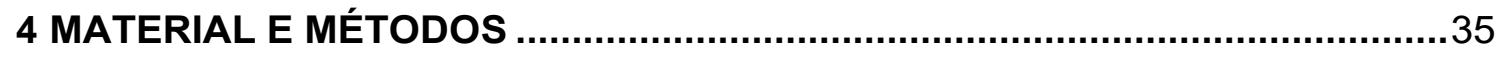

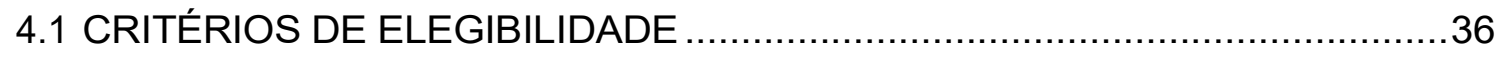

4.2 FONTE DE INFORMAÇÃO E ESTRATÉGIA DE BUSCA. .............................. 36

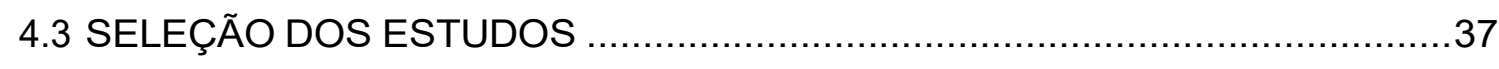

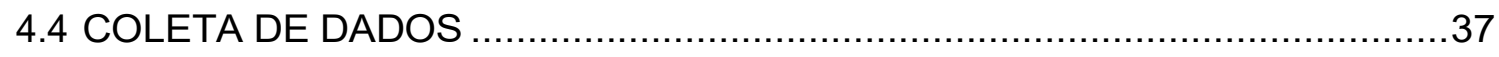

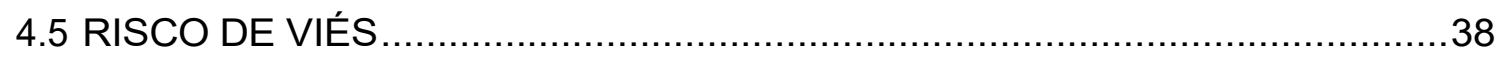

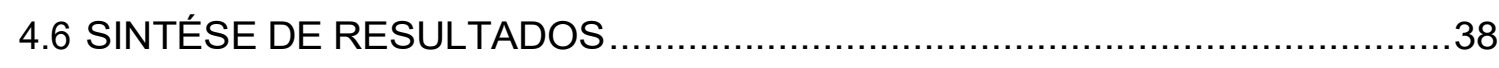

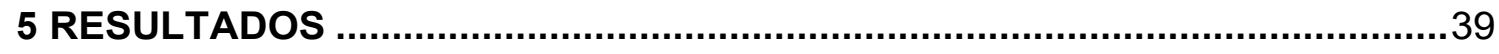

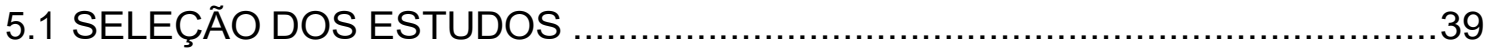

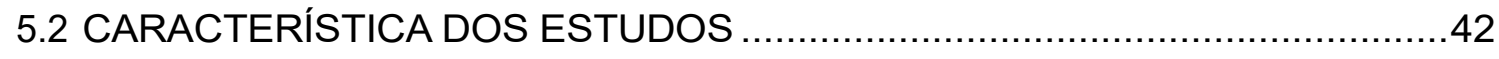

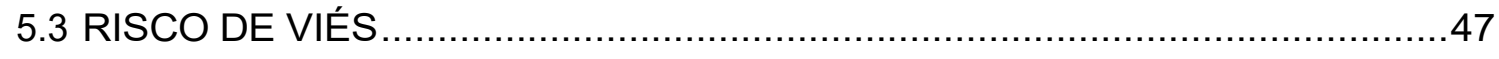

5.4 RESULTADOS INDIVIDUAIS DOS ESTUDOS .......................................... 48

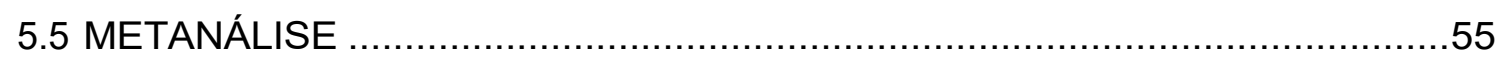

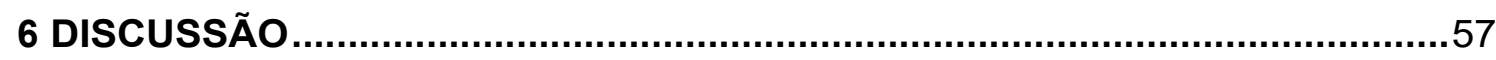

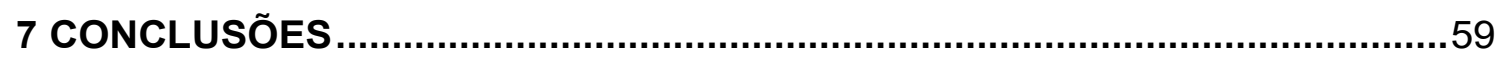

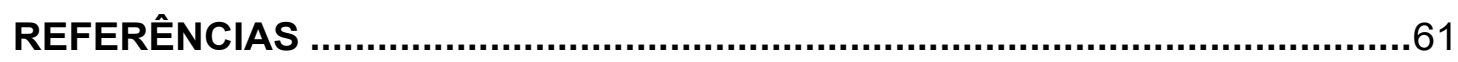





\section{INTRODUÇÃO}

A infecção cruzada é causada pela transmissão de microrganismos de um paciente para outro através do operador, ambiente e/ou instrumentos contaminados (Rautemaa et al., 2006; Zemouri et al., 2017). Uma importante fonte de infecção cruzada no consultório odontológico são os aerossóis, que são partículas líquidas ou sólidas suspensas no ar que podem conter microrganismos. Muitos procedimentos odontológicos, como o uso de aparelhos ultrassônicos, peças de mão, alta rotação, baixa rotação e seringa tríplice, geram essas partículas (Klyn et al., 2001; Feres et al., 2010; Dawson et al., 2016; Retamal-Valdes et al., 2017). Há evidências de que o aerossol pode atingir uma distância de um a três metros de sua fonte, causando contaminação de superfícies distantes (Logthetis; Martinez-Welles, 1995; Barker; Jones, 2005; Rautemaa et al., 2006).

Partículas de aerossol geradas por procedimentos odontológicos podem conter bactérias (como Mycobacterium tuberculosis, Staphylococcus spp e Streptococcus spp.) e vírus (como o vírus da imunodeficiência humana, vírus da hepatite $B$, hepatite $C$ e Herpes Simplex), entre outros agentes infecciosos (Gralton et al., 2011; Cowling et al., 2013; Zemouri et al., 2017). Esses microrganismos podem permanecer suspensos por longos períodos, mantendo sua infectividade (Grenier, 1995; Cowling et al., 2013). Consequentemente, podem ser inalados ou transmitidos por contato direto com as membranas mucosas do trato respiratório e membrana ocular (Plotkowski et al., 1993; Browning; McCarthy, 2012; Cowling et al., 2013).

O uso de enxaguatórios bucais pré-procedimento tem sido proposto para evitar a contaminação cruzada no consultório odontológico (Logthetis; MartinezWelles, 1995; Feres et al., 2010; Retamal-Valdez et al., 2017). Há evidência de que enxaguatórios bucais contendo clorexidina (CHX) (Van Strydonck et al., 2012), cloreto de cetilpiridínio(CPC) (Haps et al., 2008) e óleos essenciais (EOs) (Haas et al., 2016) são eficazes na redução da placa e gengivite. No entanto, até o momento, nenhuma revisão sistemática avaliou a eficácia desses produtos na redução microrganismos disseminados pelo aerossol. Além disso, o risco de viés nesses estudos não foi abordado em nenhum estudo anterior. Assim, esta revisão tem como objetivo responder a seguinte pergunta focada: "Em pacientes submetidos a procedimentos 
Odontológicos que geram aerossol, o uso de enxaguatório bucal pré-procedimento reduz o número de microrganismos no aerossol quando comparado com enxágue com placebo ou nenhum enxágue?". 


\section{REVISÃO DE LITERATURA}

\subsection{INFECÇÃO CRUZADA E O RISCO DE TRANSMISSÃO DE DOENÇAS}

A cavidade oral é um local favorável à transmissão, inoculação e crescimento de microrganismos. Sangue e saliva agem como veículos que podem conter diversos tipos de patógenos, incluindo bactérias, fungos e vírus (CDC,1986; Zemouri et al., 2017). O cirurgião dentista apresenta maior risco de contaminação por estes agentes, devido à exposição aos mesmos durante a prática clínica (Pankhurst; Coulter, 2009). Existem muitas vias de transmissão de agentes infeciosos na prática odontológica. Essa transmissão pode ocorrer de maneira direta (pelo contato direto entre o portador e o hospedeiro); indireta (o hospedeiro entra em contato com uma superfície ou substância contaminada) e à distância (por exemplo, o hospedeiro entra em contato com o microrganismo, através do ar) (Miller, 1993). As vias de transmissão também são variadas, podendo ocorrer por: inoculação (por exemplo: ferimentos por instrumentais durante procedimentos cirúrgicos), inalação de aerossóis ou gotículas, absorção através da pele sem ferimentos ou com ferimentos, absorção através das membranas mucosas (incluindo olhos) e ingestão (Cotonne et al., 1996).

Zemouri et al. (2017) identificou em sua revisão 38 tipos de microrganismos que podem ser transmitidos no consultório odontológico. Entre esses, foram identificadas dezenove bactérias Gram-negativas e Gram-positivas, tais como: Mycobacterium tuberculosis, Staphylococcus aureus, Streptococcus spp. e Aspergillus sp., que têm sua origem na água da cadeira odontológica, pele humana e cavidade oral.

Cerca de um terço da população mundial está infectada com Mycobacterium tuberculosis, o principal agente causador da tuberculose. A doença possui um período de latência muito grande, portanto os sintomas podem começar a se manifestar após meses ou até anos após a contaminação. (CDC, 2005)

O Staphylococcus aureus é um microrganismo comensal da pele e nasofaringe e é detectado em cavidades orais de cerca de 30\% das pessoas (Kurita etal., 2006). É transmitido principalmente através de contato com fluidos e está 
associado com uma ampla gama de infecções que variam de lesões superficiais a infecções profundas, tais como sepse, artrite, endocardite ou pneumonia. Toxinas produzidas por $S$. aureus podem causar envenenamento ou síndrome do choque tóxico. Na cavidade bucal, $S$. aureus pode ser responsável por queilite angular, parotidite, osteomielite ou mucosite (O'Leary et al., 2011).

Além das infecções bacterianas, os vírus também representam um risco de contaminação. Apesar do HIV ser a doença infectocontagiosa mais temida, seu potencial de contaminação é baixo. Estudos prospectivos em todo o mundo indicam que o risco médio de infecção por HIV depois de uma única exposição percutânea por sangue contaminado é de 0,3\% (variando de 0,2\%- 0,5\% (Bell, 1997). Após uma exposição de membranas mucosas dos olhos, nariz ou boca, o risco é aproximadamente 0, 1\% (Ippolito et al., 1993). Já as Hepatites possuem alto risco de transmissão pela saliva. Estudos mostram que o vírus da hepatite $\mathrm{C}$ pode se manter ativo por até 48 horas em superfícies contaminadas (Ansaldi et., al 2014). O dentista e sua equipe tem um risco entre 3 e 6 vezes maior de contrair hepatite $B$ quando comparado com a população em geral (Burgardt; Leão, 1997). São suficientes minúsculas quantidades de sangue ou saliva $(0,00004 \mathrm{ml})$ para que ocorra a transmissão, e os riscos de contaminação, durante e após procedimentos invasivos, são de 30\% a 50\% (Gunson et al., 2003).

As infecções respiratórias causadas por vírus também representam um risco de infecção cruzada. Muitos vírus diferentes causam doenças respiratórias, incluindo o resfriado comum (rinovírus), coronavírus, adenovírus e influenza. Influenza A é uma preocupação maior, já que a infecção pode ser grave. Em alguns casos, o vírus influenza A leva a complicações como bronquite e pneumonia secundária, que podem ser fatais (Husain, 2014). 


\subsection{AEROSSÓIS}

Aerossóis são partículas sólidas ou líquidas suspensas (por pelo menos alguns segundos) em um gás. O tamanho das partículas pode variar de 0,001 a mais de $100 \mu \mathrm{m}$ (Hinds, 1982). O uso de certos dispositivos como: ultrassom, peças de mão, alta rotação, baixa rotação e seringa tríplice podem espalhar os aerossóis contendo microrganismos no ambiente clínico (Veena et al., 2015).O aerossol

produzido durante o tratamento odontológico sai da cavidade bucal do paciente e se mistura ao ar presente no ambiente, alterando a sua composição (Szymańska, 2007). Essas partículas podem ser inaladas e penetrar facilmente nos alvéolos pulmonares. Além de inaladas, as partículas também podem contaminar a mucosa ocular. Muitas doenças têm como porta de entrada a mucosa ocular, entre essas podemos destacar a Hepatite B (World Health Organization, 2007).

As partículas de aerossol geradas por instrumentos podem conter vírus, como os da síndrome de imunodeficiência adquirida (AIDS), hepatite B (HBV) e hepatite C, Herpes Simplex entre outras doenças (Toroglu et al., 2003). Além dos vírus, bactérias como o Mycobacterium tuberculosis, e Staphylococcus aureus também podem estar presentes nessas partículas (Kuritaet et al., 2006; Leggat; Kedjarune, 2001). Esses microrganismos podem permanecer suspensos em aerossóis e manter a infectividade por longos períodos, comprometendo a saúde dos pacientes e profissionais (Grenier, 1995; Timmerman et al., 2004; Cowling et al., 2013). Há evidência que o aerossol gerado pode alcançar uma distância de um até três metros a partir da sua fonte geradora, provocando contaminação de superfícies distantes (Logthetis; Martinez-Welles, 1995; Barker; Jones., 2005).

\subsection{METODOS DE CONTROLE OU PREVENÇÃO DE INFECÇÃO CRUZADA}

$\mathrm{Na}$ prática diária o cirurgião dentista está exposto a sangue, fluidos corporais, secreções e excreções. (Stokowski et al., 2011). Todos os pacientes devem ser considerados como possíveis transmissores de agentes patogênicos e devem ser submetidos a precauções universais para controle de infecção (Cottone; 
Molinari,1991). Em muitos casos, o sangue e a saliva não são visíveis, mas ainda podem estar presentes em pequenas quantidades sendo considerados materiais potencialmente infecciosos e possíveis transmissores de doenças (CDC, 2003). Muitos pacientes podem ser portadores assintomáticos de patógenos, ou seja, podem conter o mesmo sem apresentar os sintomas da doença (Jakubovics et al., 2014).

O princípio subjacente de controle de infecção cruzada envolve precauções padronizadas para minimizar o risco de transmissão, independentemente do estado de saúde do paciente ou do profissional de saúde. Um eficaz controle de infecção cruzada requer constante vigilância e envolve os esforços combinados de toda a equipe odontológica (Pankhurst; Coulter, 2009). Práticas preventivas devem ser adotadas para reduzir a exposição e possíveis contaminações. Entre estas, podemos citar: manuseio cuidadoso no uso de instrumentos cortantes; uso de aventais para minimizar o contato com respingos de sangue; lavagem constante das mãos; uso de barreiras (como luvas, máscaras, óculos de proteção) e utilização de enxaguatórios bucais pré-procedimentos (Weissfeld, 2014).

As superfícies no consultório odontológico são consideradas contaminadas devido à geração de aerossóis durante os procedimentos (Retamal-Valdez et al., 2017). Os materiais de proteção de barreira podem prevenir contaminação de superfícies. As barreiras utilizadas para cobrir as superfícies não são impermeáveis à umidade e devem ser removidas e descartadas entre os pacientes (Thomas et al., 2014). Além das barreiras, o uso de desinfetantes também é indicado. As superfícies devem ser limpas com um desinfetante capaz de eliminar vírus, bactérias, fungose ter atividade hidrofílica e lipofílica (CDC, 2003).

A utilização de EPls também é fundamental para a proteção do cirurgião dentista. A máscara é usada principalmente para cobrir as mucosas, impedindo que aerossóis com patógenos penetrem na mucosa oral e nasal (Szymańska, 2007). O requisito mínimo aceito para uma máscara é de 95 por cento de filtração de partículas com tamanho de três a cinco micra (CDC, 2003). Os óculos de proteção impedem contaminação da mucosa ocular. Muitas doenças têm como porta de entrada a mucosa ocular, entre essas podemos destacar a Hepatite B. (Department of Labor; Occupational Safety and Health Administration, 1989). A utilização de aventais descartáveis para proteção da pele e vestimentas é indispensável. Estudos de coloração provaram que traje clínico torna-se facilmente contaminado sempre 
que um instrumento que propaga aerossol é utilizado na cavidade bucal (Stokowski et al., 2011).

A higienização das mãos reduz consideravelmente o número de microrganismos na superfície da pele e é considerada a medida mais importante para reduzir o risco de transmissão de microrganismos aos pacientes e aos profissionais de saúde (Larson et al., 2000). Estudos realizados em hospitais demonstraram que o não cumprimento das práticas de higiene das mãos está associado a infecções associadas aos cuidados de saúde e à disseminação de organismos multirresistentes. O não cumprimento também tem sido um dos principais contribuintes para os surtos de infecção (Larson, 1995).

A utilização de enxaguatórios bucais antes de procedimentos clínicos também constitui um método de controle de infecção cruzada no consultório odontológico. Bochechos pré-procedimento podem diminuir o número de microrganismos na cavidade bucal e consequentemente reduzir o risco de contaminação cruzada.

\subsection{EXAGUATÓRIOS BUCAIS}

Os enxaguatórios bucais foram desenvolvidos principalmente para o controle químico adjunto do biofilme dentário, resultando em benefícios adicionais na redução da gengivite (Van Strydonck et al., 2012). Um agente antimicrobiano ideal deve ter potencial contra biofilme bacteriano, gerando uma redução da adesão bacteriana às superfícies dentais e mucosas orais; inibindo o crescimento e proliferação de outros microrganismos; reduzindo a formação de produtos citotóxicos e promovendo o desenvolvimento de uma microbiota menos patogênica (Feres et al., 2010). O princípio de ação pode ser por rompimento da parede celular bacteriana ou inibição dos complexos de enzimáticos, levando a uma diminuição da atividade metabólica (Cowan, 1999).

Os enxaguatórios bucais com maior evidência de eficácia na redução de placa e gengivite são clorexidina, óleos essenciais e cloreto de cetilpiridinio.

A clorexidina $(\mathrm{CHX})$ é constituída por dois anéis fenólicos clorados ligados por uma cadeia de hexametileno. Esses anéis estão ligados de maneira simétrica à 
cadeia (Denton, 2001). Como essas moléculas são positivas e as superfícies bacterianas são negativas, ocorre uma força de atração com adsorção, aumentando a permeabilidade bacteriana e permitindo a entrada da clorexidina no meio citoplasmático bacteriano, levando a ruptura da membrana e morte celular (Yates et al., 2002). Apresenta ação contra bactérias Gram-negativas e Gram-positivas, com efetividade mesmo na presença de sangue (Keijser et al., 2003). Também possui boa substantividade, ou seja: capacidade de ficar retida na cavidade bucal e ser liberada lentamente (García-Caballero et al., 2013). A clorexidina tem baixa toxicidade, pois apresenta baixa absorção no trato gastrointestinal, sendo quase totalmente excretada (Bambace, 2003). É considerada o padrão ouro dos agentes químicos no controle da placa e gengivite, por sua maior eficácia em relação aos demais agentes químicos (Van Strondyk et al., 2012). Apesar da sua eficácia, seu uso contínuo pode provocar o desenvolvimento de manchas dentais, alteração no paladar e descamação da mucosa oral (McCoy et al., 2008).

O Cloreto de cetilpiridínio (CPC) é um composto catiônico, tensoativo, monovalente, pertencente ao grupo dos compostos quaternários de amônia. Apresenta eficácia contra microrganismos Gram-positivos, Gram-negativos e leveduras (Roberts; Addy, 1981; Rösing et al., 2017); A forma de ação desse agente é relacionada ao aumento da permeabilidade da parede celular da bactéria, favorecendo a sua lise, bem como a redução no metabolismo e a interrupção da capacidade do microrganismo para aderir à superfície do dente. Diferente da clorexidina apresenta baixas substantividade (Haps et al., 2008). Yévenes et al. (2003) relatam que, após uma hora da exposição ao enxaguatório, o biofilme volta a crescer. Sua efetividade depende da concentração empregada (Corbin et al., 2011). Apresenta evidência de efeito benéfico adicional pequeno, porém significativo, no controle de placa e gengivite (Haps et al., 2008). Seu uso prolongado pode levar a sensação de ardência na mucosa, formação excessiva de cálculo e formação de manchas dentais, devido à sua interação com corantes dos alimentos (Yantes et al., 2002).

Óleos essenciais (OE) também apresentam efeito bactericida contra bactérias do biofilme bucal (Pan et al., 2000). Agem principalmente sobre as bactérias Gram-positivas, Gram-negativas e leveduras (Ouhayoun, 2003). Apresentam baixa substantividade, porém elevada capacidade de interação com certos componentes do biofilme bacteriano, além de boa penetração no mesmo 
(Ouhayoun, 2003). Também apresentam boa evidência de ação anti-placa e antigengivite (Cortelli et al., 2014; Haas et al., 2016). Os efeitos colaterais mais frequentes são sensação de queimação e gosto amargo (Fine et al.,1993).

Estudos demostram que enxaguatórios bucais exercem efeito contra a massa microbiana total e resultam em uma diminuição geral tanto na biomassa bacteriana quanto na atividade metabólica (Charles et al., 2000). Okuda et al. (1998) mostraram que após um bochecho de 30 segundos com $20 \mathrm{ml}$ da solução de óleos essenciais, houve eliminação de diversas bactérias na saliva, tais como: Staphylococcus aureus, Streptococcus pyogenes, Helicobacter pylori, Candida albicans, Streptococcus mutans, Actinomyces viscosus, Porphyromonas gingivalis, Prevotella intermedia e Actinobacillus actinomycetemcomitans resistentes à meticilina. Além dessas bactérias, ocorreu também a inativação dos vírus da imunodeficiência humana. Fine et al. (2000) demostrou em seu estudo que enxague com óleos essenciais produziu reduções de $69,9 \%$ e $75,4 \%$ no número total de estreptococos sp. e S. mutans na placa, respectivamente; bem como reduções de $50,8 \%$ e $39,2 \%$ dos mesmos microrganismos na saliva. Por sua vez, Meiller et al. (2005) demostrou eficácia clínica de enxague com óleos essenciais na redução da presença de vírus em fluidos orais por pelo menos 30 minutos após o enxague, demostrando que o risco de contaminação cruzada durante o tratamento odontológico pode ser reduzido com a utilização do enxaguatórios.

A clorexidina também se mostra eficiente na redução de microrganismos. Bochecho com gluconato de clorexidina a $0,12 \%$ resultou em reduções significativas, após 3 e 6 meses de seu uso, nos números de anaeróbios totais, aeróbios totais, estreptococos e Actinomyces sp (Walker,1988).

O cloreto de cetilpiridínio (CPC) também demostra ser eficiente na redução de patógenos salivares. Elworthy et al. (1996) observou que bochechos de 60 segundos com CPC promoveram redução de bactérias anaeróbias totais significativamente maiores que controle negativo entre 180 e 300 minutos após o uso do produto. 


\section{PROPOSIÇÃO}

O objetivo dessa revisão sistemática foi avaliar a evidência sobre a eficácia de enxaguatórios pré-procedimentos na redução do número de microrganismos no aerossol, em comparação a nenhum enxague ou enxague com placebo. 


\section{MATERIAL E MÉTODOS}

O protocolo de estudo desta RS foi registrado na base de registro PROSPERO (International Prospective Register of Systematic Reviews) com o número CRD4201809020.

O texto da revisão foi estruturado de acordo com as diretrizes do PRISMA (Preferred Reporting Items for Systematic Reviews and Meta-Analyses) (Moher et al., 2015), do Cochrane Handbook of Systematic Reviews of Interventions (Higgins; Green 2011), bem como Check Review (Chambrone et al., 2010).

\subsection{CRITÉRIOS DE ELEGIBILIDADE}

\section{Tipo de Estudos e participantes}

Foram selecionados estudos randomizados que incluíram pacientes submetidos a algum procedimento odontológico que gera aerossol, tais como: profilaxia, instrumentação ultrassônica, remoção de aparelho ortodôntico, alta rotação para a confecção de preparos dentários, entre outros. Foram incluídos estudos com pacientes saudáveis, com gengivite ou periodontite.

\section{Intervenção e comparação}

Uso de um enxaguatório bucal com algum princípio ativo antes do procedimento odontológico, em comparação com nenhum enxaguatório ou utilização de controle negativo (placebo ou água) antes do procedimento odontológico.

\section{Desfechos}

Redução percentual média no número de bactérias viáveis presentes no aerossol. 


\section{Critério de exclusão:}

Foram excluídos estudos não randomizados, estudos que não possuíam um grupo de controle (nenhum enxaguatório ou controle negativo) para comparação, estudos in vitro, estudos em animais, cartas ao editor e revisões.

\subsection{FONTES DE INFORMAÇÃO E ESTRATÉGIA DE BUSCA}

As estratégias de busca foram desenvolvidas para as seguintes bases de dados: MEDLINE via PudMed, EMBASE, LILACS e GOOGLE ACADÊMICO. A estratégia de busca utilizou termos livres e termos $\mathrm{MesH}$, dispostos em várias combinações com a ajuda de operadores booleanos. Não houve restrição de idioma. A data da última busca foi março de 2018.

A seguinte estratégia de busca foi elaborada no MEDLINE:

\# 1 anti-infective agents, local OR antiseptics or chlorhexidine OR chlorhexidine gluconate OR essential oils OR listerine or oils, volatile OR tartar control listerine OR cetylpyridinium OR cetylpyridinium chloride, zinc acetate drug combination OR herbal OR benzethonium OR benzalkonium compounds \#2 mouthwash OR mouthrinse OR rinse OR prevention mouthrinse OR dental \#3\#1 AND \#2

\#4 contamination OR air contamination OR aerosol OR aerosols \#3 AND \#4

Além da busca eletrônica, uma busca manual foi realizada utilizando listas de referências dos artigos selecionados. 


\subsection{SELEÇÃO DE ESTUDOS}

$\mathrm{Na}$ primeira fase, dois revisores (VCM e MLS) selecionaram títulos e resumos de forma independente. Discordâncias foram resolvidas por discussão com um terceiro revisor (CMP). Os estudos que pareciam atender aos critérios de inclusão, ou que precisaram de informações adicionais, foram selecionados para avaliação completa na segunda fase. Os textos completos foram avaliados de forma independente pelos mesmos revisores, a fim de determinar se o estudo era elegível. Os estudos que atenderam aos critérios de inclusão foram submetidos à extração de dados e avaliação do risco de viés. As razões para a rejeição dos estudos foram registradas.

\subsection{COLETA DE DADOS}

Todos os dados foram extraídos individualmente por dois revisores (VCM e MLS). Discordâncias foram discutidas com um terceiro revisor (CMP). No caso de dúvidas, os autores dos estudos incluídos foram contatados para fornecer informações adicionais ou que estivessem faltando. Os dados foram extraídos e registrados utilizando formulários de extração desenvolvidos especificamente para essa revisão.

As seguintes variáveis foram analisadas: 1) citação do estudo, 2) país e local do estudo, 3) características dos participantes, 4) tipo de procedimento odontológico que gerou aerossol, 5) tipo de coleta microbiológica, 6) análise microbiológica, 7) antisséptico utilizado (incluindo concentração e tempo de enxágue), 8) medidas de desfecho, 9) conclusões do autor e 10) fonte de financiamento e conflitos de interesse. 


\subsection{RISCO DE VIÉS}

Cada estudo recebeu avaliação de risco de viés de acordo com a ferramenta Cochrane Collaboration's Tool for Assessing Risk of Bias (Higgins\& Green 2011). A avaliação da qualidade dos estudos foi realizada individualmente, por dois revisores distintos (VCM e MLS). Qualquer discordância entre esses dois avaliadores foi resolvida por um terceiro revisor (CMP). Em resumo, os estudos foram avaliados conforme os seguintes domínios relacionados a risco de viés: geração de sequência aleatória e sigilo de alocação (viés de seleção), cegamento dos participantes de pesquisa e cegamento do operador (viés de desempenho), cegamento do responsável pela avaliação do desfecho (viés de detecção), dados incompletos de desfecho (viés de atrito) e relato seletivo de desfecho (viés de relato), além de relato ou não de cálculo de tamanho de amostra.

De acordo com a avaliação dos domínios acima, os estudos foram classificados em:

(1) Baixo risco de viés: se todos os critérios foramatendidos;

(2) Risco incerto de viés: se um ou mais critérios foram parcialmente cumpridos ou não foram claramente descritos no artigo;

(3) Alto risco de viés: se um ou mais critérios não foram cumpridos.

\subsection{SÍNTESE DE RESULTADOS}

A Meta-análises foi realizada utilizando um software (Review Manager, versão 5.3, The Nordic Cochrane Center, The Cochrane Collaboration, Copenhague, Dinamarca). Meta-análises de efeitos aleatórios foram realizadas para o desfecho redução de bactérias viáveis, que foi expressa como redução percentual média de unidades formadoras de colônia (UFCs) após o enxágue. A redução percentual média de UFCs foi calculada a partir da diferença entre a média inicial e final de UFCs. A combinação de resultados dos estudos foi expressa como diferença média ponderada (WMD, do inglês weighted mean difference). A magnitude da heterogeneidade entre os estudos foi avaliada com o teste $\mathrm{I}^{2}$. 


\section{RESULTADOS}

\subsection{SELEÇÃO DOS ESTUDOS}

$\mathrm{Na}$ primeira fase do processo de seleção dos estudos, 725 artigos potencialmente relevantes foram encontrados nas bases de dados eletrônicas e na busca manual. Após revisão de títulos ou resumos, 704 foram excluídos. Os textos completos das 22 publicações restantes foram revisados. Após a leitura completa desses artigos, 10 estudos foram excluídos, pelos seguintes motivos:

- Randomização para tipo de enxaguatório bucal não foi realizada (Woral et al., 1987, Toroglu et al., 2001, Deveker et al., 2012 e Santos et al., 2014, Kaur et al., 2014),

- Revisão narrativa (Dunn 1999),

- Todos os sujeitos receberam enxaguatório bucal com clorexidina (Muir et al., 1978),

- Carta ao editor (Stirrups, 1987),

- Ausência de grupo controle (Suresh et al., 2011)e

- Texto completo não disponível e não obtido mesmo após entrar em contato com o autor (Yengopal 2004).

Doze estudos foram selecionados para síntese qualitativa e quatro estudos foram incluídos na síntese quantitativa (meta-análise) (Figura 5.1). 


\subsection{Diagramas dos Estudos Selecionados}

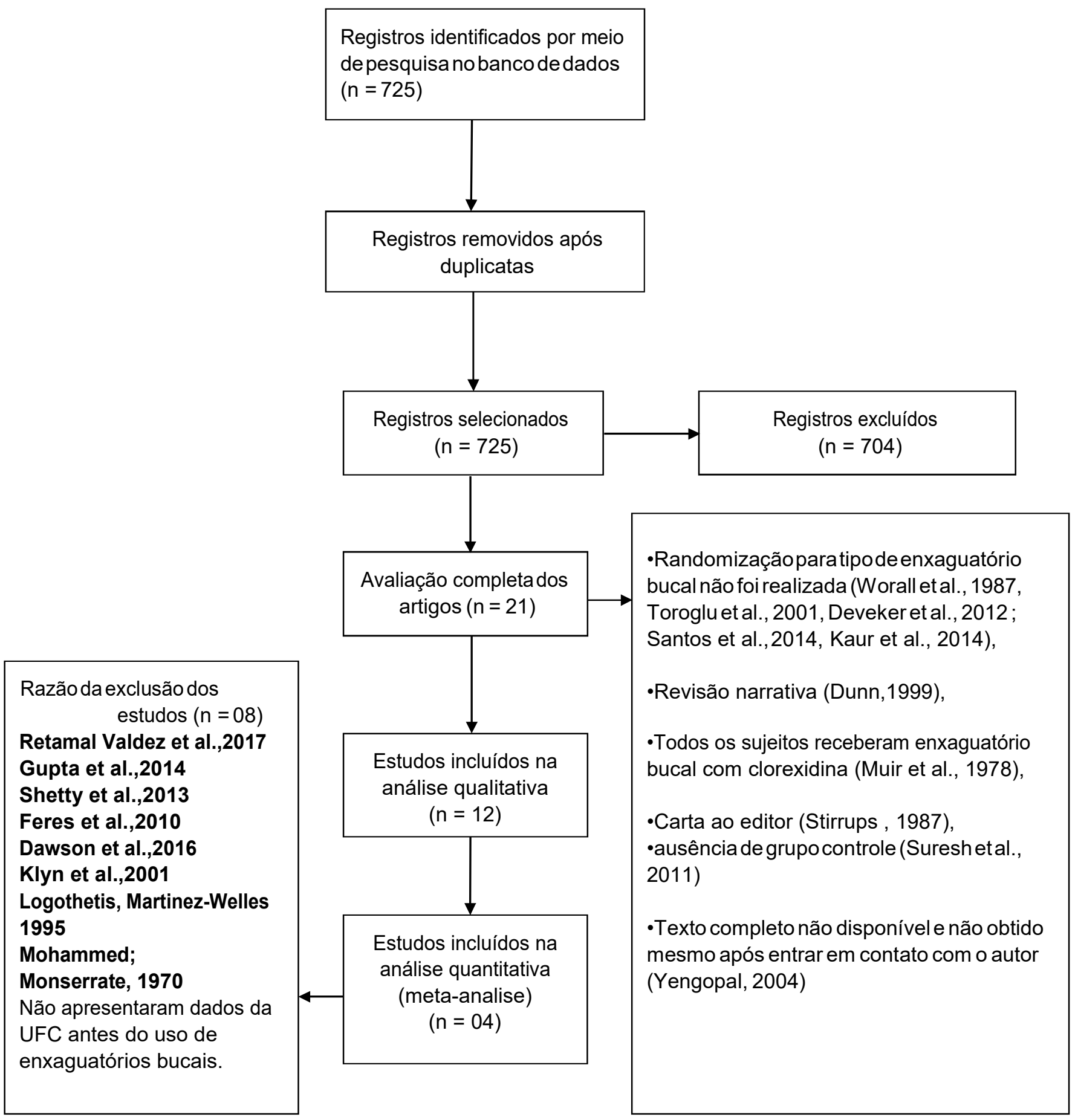




\subsection{CARACTERÍSTICAS DOS ESTUDOS}

As características dos estudos incluídos são mostradas na Tabela 5.1. No total, 367 indivíduos foram incluídos. Na maioria dos estudos, o dispositivo gerador de aerossol foi o aparelho ultrassônico (Retamal-Valdes et al., 2017, Gupta et al., 2014, Shetty et al., 2013, Feres et al., 2010, Klyn et al., 2001, Fine et al., 1993a estudo 1, Fine et al., 1993a estudo 2, Fine et al., 1993b e Fine et al., 1992). Nos demais estudos, os aerossóis foram gerados por baixa rotação para polimento de superfícies dentárias (Logothetis; Martinez-Welles, 1995), caneta de alta rotação para preparo de cavidades dentárias (Mohammed; Monserrate, 1970) e caneta de baixa rotação para remoção de aparelhos ortodônticos (Dawson et al., 2016).

Todos os estudos do grupo do autor Fine (Fine et al., 1993a estudo 1, Fine et al., 1993a estudo 2, Fine et al., 1993b e Fine et al., 1992) e Dawson et al. (2016) coletaram amostras microbiológicas com filtros estéreis e conectados a um tubo de

entrada especialmente adaptado, inserido em um sugador a vácuo. Mohammed; Monserrate (1970) usou um precipitador estéril conectado a um sugador para coletar o ar da amostra. Outros estudos usaram placa de ágar-sangue (Gupta et al., 2014; Feres et al., 2010; Klyn et al., 2001; Logothetis; Martinez-Welles, 1995), placa de ágar HNK (Retamal-Valdes et al., 2017) e placas de ágar de soja (Shetty et al., 2013). Nestes estudos, placas de ágar foram posicionadas em diferentes locais do consultório odontológico; com distâncias variáveis do ponto de referência (a boca do paciente).

Quanto à análise microbiológica, a maioria dos estudos contou o número total de unidades formadoras de colônia (UFC) (Retamal-Valdes et al., 2017, Gupta et al., 2014, Shetty et al., 2013, Feres et al., 2010, Klyn et al., 2001, Logothetis; Martinez-Welles, 1995, Fine et al., 1993a estudo 1, Fine et al., 1993a estudo 2, Fine et al., 1993b e Fine et al., 1992; Mohammed; Monserrate, 1970). O estudo de Dawson et al. (2016) utilizou reação em cadeia da polimerase (PCR) para avaliar as contagens bacterianas. Além disso, Retamal-Valdes et al. (2017) e Feres et al. (2010) também usaram a técnica de hibridização DNA-DNA checkerboard na avaliação de microrganismos. 
Tabela 5.1 - Características dos estudos incluídos.

\begin{tabular}{|c|c|c|c|c|c|c|}
\hline Estudo e País & $\begin{array}{l}\text { Desenho do } \\
\text { estudo }\end{array}$ & $\begin{array}{l}\text { Tamanho da } \\
\text { amostra (início do } \\
\text { estudo) }\end{array}$ & Procedimento & $\begin{array}{l}\text { Método de coleta do } \\
\text { aerossol }\end{array}$ & $\begin{array}{l}\text { Análise } \\
\text { microbiológica }\end{array}$ & $\begin{array}{l}\text { Fonte de } \\
\text { financiamento }\end{array}$ \\
\hline $\begin{array}{l}\text { Retamal-Valdez } \\
\text { et al. (2017) } \\
\text { (Brasil) }\end{array}$ & $\begin{array}{l}\text { Ensaio clínico } \\
\text { aleatorizado } \\
\text { paralelo }\end{array}$ & $\begin{array}{l}\mathrm{N}=60 \text { (24 homens, } \\
36 \text { mulheres) } \\
\text { Idade: } 18-70 \text { anos }\end{array}$ & $\begin{array}{l}\text { Profilaxia dentária } \\
\text { de boca toda com } \\
\text { aparelho de } \\
\text { ultrassom por } 10 \\
\text { minutos }\end{array}$ & $\begin{array}{l}5 \text { placas de agar HNK: } 3 \text { na } \\
\text { placa de suporte, } 1 \text { no peito } \\
\text { do voluntário e } 1 \text { na testa } \\
\text { do operador }\end{array}$ & $\begin{array}{l}\text { 1) Cultura anaeróbica. } \\
\text { Contagem de } \\
\text { unidades formadoras } \\
\text { de colônias (UFCs) } \\
\text { com contador de } \\
\text { Colônias Lab Line } \\
\text { 2) Checkerboard DNA- } \\
\text { DNA hybridization (40 } \\
\text { especies) }\end{array}$ & $\begin{array}{l}\text { Colgate } \\
\text { Palmolive } \\
\text { (Piscataway, } \\
\text { USA) e Latin } \\
\text { America Oral } \\
\text { Health } \\
\text { Association } \\
\text { (LAOHA). }\end{array}$ \\
\hline $\begin{array}{l}\text { Dawson et al. } \\
(2016) \\
\text { (Reino Unido) }\end{array}$ & $\begin{array}{l}\text { Ensaio clínico } \\
\text { aleatorizado } \\
\text { paralelo }\end{array}$ & $\mathrm{N}=18$ & $\begin{array}{l}\text { Caneta de baixa } \\
\text { rotação }\end{array}$ & $\begin{array}{l}\text { Impactador de Andersen de } \\
6 \text { estágios para partículas } \\
\text { ligado a uma bomba de } \\
\text { vácuo. Cada um dos } 6 \\
\text { estágios do Impactado } \\
\text { continha uma placa de } \\
\text { Petri com ágar anaeróbio. } \\
\text { A entrada de ar do tubo de } \\
\text { extensão foi posicionada } \\
\text { ao nível da boca do } \\
\text { paciente e a uma distância } \\
\text { de } 30 \mathrm{~cm} \text { da mesma }\end{array}$ & $\begin{array}{l}\text { 1) Cultura anaeróbica } \\
\text { (crescimento } \\
\text { bacteriano total) } \\
\text { 2) Reação em cadeia } \\
\text { da polimerase } \\
\text { (Universal primer) para } \\
\text { bactérias totais }\end{array}$ & $\begin{array}{l}\text { Não houve } \\
\text { finaciamento }\end{array}$ \\
\hline $\begin{array}{l}\text { Gupta et al. } \\
(2014) \\
\text { (índia) }\end{array}$ & $\begin{array}{l}\text { Ensaio clínico } \\
\text { aleatorizado } \\
\text { paralelo }\end{array}$ & $\begin{array}{l}\mathrm{N}=24 \\
16 \text { homens e } \\
08 \text { mulheres } \\
\text { Idade: } \\
25 \text { a } 55 \text { anos }\end{array}$ & $\begin{array}{l}\text { Profilaxia dentária } \\
\text { de boca toda com } \\
\text { aparelho de } \\
\text { ultrassom por } 30 \\
\text { minutos }\end{array}$ & $\begin{array}{l}3 \text { placas de ágar-sangue: } 1 \\
\text { no peito do paciente, } 1 \text { no } \\
\text { peito do operador e } 1 \text { no } \\
\text { peito do assistente. }\end{array}$ & $\begin{array}{l}\text { Contagem de } \\
\text { unidades formadoras } \\
\text { de colônias (CFUs) }\end{array}$ & $\begin{array}{l}\text { Não houve } \\
\text { finaciamento }\end{array}$ \\
\hline
\end{tabular}




\begin{tabular}{|c|c|c|c|c|c|c|}
\hline $\begin{array}{l}\text { Shetty et al. } \\
(2013) \\
\text { (índia) }\end{array}$ & $\begin{array}{l}\text { Ensaio clínico } \\
\text { aleatorizado } \\
\text { paralelo }\end{array}$ & $\begin{array}{l}\mathrm{N}=60 \\
\text { Idade: } 25-45 \text { anos }\end{array}$ & $\begin{array}{l}\text { Profilaxia dental } \\
\text { com o uso de } \\
\text { ultrassom }\end{array}$ & $\begin{array}{l}\text { 3placas de agar TSA } \\
\text { colocadas no: } \\
6 \text { polegadas de distânciado } \\
\text { nariz do operador } \\
\text { - } 6 \text { Polegadas de } \\
\text { distânciado assistente de } \\
\text { dentista } \\
\text { - } 12 \text { Polegadas de } \\
\text { distânciado peito do } \\
\text { paciente }\end{array}$ & $\begin{array}{l}\text { Contagem de } \\
\text { unidades formadoras } \\
\text { de colônias (CFUs) }\end{array}$ & $\begin{array}{l}\text { Não houve } \\
\text { finaciamento }\end{array}$ \\
\hline $\begin{array}{l}\text { Feres et al. } \\
(2010) \\
\text { (Brasil) }\end{array}$ & $\begin{array}{l}\text { Ensaio clínico } \\
\text { aleatorizado } \\
\text { paralelo }\end{array}$ & $\begin{array}{l}\mathrm{N}=60 \\
\text { Idade: } 30-70 \text { anos }\end{array}$ & $\begin{array}{l}\text { Profilaxia dentária } \\
\text { de boca toda com } \\
\text { aparelho de } \\
\text { ultrassom por } 10 \\
\text { minutos }\end{array}$ & $\begin{array}{l}5 \text { placas de ágar sangue: } 3 \\
\text { na placa de suporte, } 1 \text { no } \\
\text { peito do voluntário e } 1 \text { na } \\
\text { testa do operador }\end{array}$ & $\begin{array}{l}\text { 1) Cultura anaeróbica. } \\
\text { Contagem de } \\
\text { unidades formadoras } \\
\text { de colônias (CFUs) } \\
\text { com Contador de } \\
\text { Colônias Lab Line } \\
\text { 2) Checkerboard DNA- } \\
\text { DNA hybridization (40 } \\
\text { especies) }\end{array}$ & $\begin{array}{l}\text { Colgate } \\
\text { Palmolive (São } \\
\text { Paulo, Brazil) }\end{array}$ \\
\hline $\begin{array}{l}\text { Klyn et } \\
(2001)\end{array}$ al. & $\begin{array}{l}\text { Ensaio clínico } \\
\text { aleatorizado } \\
\text { paralelo }\end{array}$ & $\begin{array}{l}\mathrm{N}=15 \\
\text { Idade: } \\
21-63 \text { anos }\end{array}$ & $\begin{array}{l}\text { Profilaxia dentária } \\
\text { de boca toda com } \\
\text { aparelho de } \\
\text { ultrassom por } 5 \\
\text { minutos }\end{array}$ & $\begin{array}{l}\text { Foram colocadas } 4 \text { placas } \\
\text { de ágar-sangue a seis } \\
\text { polegadas da cavidade } \\
\text { bucal e uma placa de ágar } \\
\text { a dois pés da cavidade } \\
\text { bucal. }\end{array}$ & $\begin{array}{l}\text { Contagem de } \\
\text { unidades formadoras } \\
\text { de colônias (CFUs) }\end{array}$ & Não \\
\hline $\begin{array}{l}\text { Logothetis; } \\
\text { Martinez- } \\
\text { Welles, (1995) } \\
\text { (EUA) }\end{array}$ & $\begin{array}{l}\text { Ensaio clínico } \\
\text { aleatorizado } \\
\text { paralelo }\end{array}$ & $\begin{array}{l}\mathrm{N}=18 \\
\text { Idade: } \\
25-54 \text { anos }\end{array}$ & $\begin{array}{l}\text { Baixa rotação para } \\
\text { polimento de } \\
\text { superfícies } \\
\text { dentárias por } 3 \\
\text { minutos }\end{array}$ & $\begin{array}{l}8 \text { placas de ágar sangue } \\
\text { distribuídas em diferentes } \\
\text { locais: na máscara do } \\
\text { operador e entre } 2 \text { e } 9 \text { pés } \\
\text { do ponto de referência } \\
\text { (cabeça do paciente) }\end{array}$ & $\begin{array}{l}\text { Cultura anaeróbica. } \\
\text { Contagem de } \\
\text { unidades formadoras } \\
\text { de colônias (CFUs) } \\
\text { com Contador de } \\
\text { Colônias Lab Line }\end{array}$ & $\begin{array}{l}\text { University Of } \\
\text { New Mexico } \\
\text { Research } \\
\text { Allocation } \\
\text { Subcommittee. }\end{array}$ \\
\hline $\begin{array}{l}\text { Fine et al. } \\
\text { (1993 a) } \\
\text { estudo1 (EUA) }\end{array}$ & $\begin{array}{l}\text { Ensaio clínico } \\
\text { aleatorizado } \\
\text { cruzado }\end{array}$ & $\begin{array}{l}\mathrm{N}=18 \\
\text { Idade e sexo não } \\
\text { reportados }\end{array}$ & $\begin{array}{l}\text { Profilaxia dentária } \\
\text { de boca toda com } \\
\text { aparelho de } \\
\text { ultrassom por } 10 \\
\text { minutos. }\end{array}$ & $\begin{array}{l}\text { Um filtro estéril contido em } \\
\text { um cassete foi posicionado } \\
\text { na frente da boca do sujeito } \\
\text { a uma distância de } 2 \\
\text { polegadas }\end{array}$ & $\begin{array}{l}\text { As UFC totais foram } \\
\text { contadas com o auxílio } \\
\text { de um } \\
\text { estereomicroscópio }\end{array}$ & $\begin{array}{l}\text { Warner-Lambert } \\
\text { Company }\end{array}$ \\
\hline Fine et al. & Ensaio clínico & $\mathrm{N}=18$ & Profilaxia dentária & Um filtro estéril contido em & As UFC totais foram & Warner-Lambert \\
\hline
\end{tabular}




\begin{tabular}{|c|c|c|c|c|c|c|}
\hline $\begin{array}{l}\text { (1993 a) estudo } \\
2 \text { (EUA) }\end{array}$ & $\begin{array}{l}\text { aleatorizado } \\
\text { cruzado }\end{array}$ & $\begin{array}{l}\text { Idade e sexo não } \\
\text { reportados }\end{array}$ & $\begin{array}{l}\text { de boca toda com } \\
\text { aparelho de } \\
\text { ultrassom por } 5 \\
\text { minutos. }\end{array}$ & $\begin{array}{l}\text { um cassete foi posicionado } \\
\text { na frente da boca do sujeito } \\
\text { a uma distância de } 2 \\
\text { polegadas }\end{array}$ & $\begin{array}{l}\text { contadas com o auxílio } \\
\text { de um } \\
\text { estereomicroscópio }\end{array}$ & Company \\
\hline $\begin{array}{l}\text { Fine et al. } \\
\text { (1993b) } \\
\text { (EUA) }\end{array}$ & $\begin{array}{l}\text { Ensaio clínico } \\
\text { aleatorizado } \\
\text { cruzado }\end{array}$ & $\begin{array}{l}\mathrm{N}=18 \\
\text { Idade e sexo não } \\
\text { reportados }\end{array}$ & $\begin{array}{l}\text { Profilaxia dentária } \\
\text { de boca toda com } \\
\text { aparelho de } \\
\text { ultrassom por } 5 \\
\text { minutos. }\end{array}$ & $\begin{array}{l}\text { Um filtro estéril contido em } \\
\text { um cassete foi posicionado } \\
\text { na frente da boca do sujeito } \\
\text { a uma distância de } 2 \\
\text { polegadas }\end{array}$ & $\begin{array}{l}\text { As UFC totais foram } \\
\text { contadas com o auxílio } \\
\text { de um } \\
\text { estereomicroscópio }\end{array}$ & $\begin{array}{l}\text { Warner-Lambert } \\
\text { Company }\end{array}$ \\
\hline $\begin{array}{l}\text { Fine et al., } \\
\text { (1992) } \\
\text { (EUA) }\end{array}$ & $\begin{array}{l}\text { Ensaio clínico } \\
\text { aleatorizado } \\
\text { cruzado }\end{array}$ & $\begin{array}{l}\mathrm{N}=18 \\
\text { Idade e sexo não } \\
\text { reportados }\end{array}$ & $\begin{array}{l}\text { Profilaxia dentária } \\
\text { de boca toda com } \\
\text { aparelho de } \\
\text { ultrassom por } 10 \\
\text { minutos. }\end{array}$ & $\begin{array}{l}\text { Um filtro estéril contido em } \\
\text { um cassete foi posicionado } \\
\text { na frente da boca do sujeito } \\
\text { a uma distância de } \\
\text { 2polegadas }\end{array}$ & $\begin{array}{l}\text { As UFC totais foram } \\
\text { contadas com o auxílio } \\
\text { de um } \\
\text { estereomicroscópio }\end{array}$ & $\begin{array}{l}\text { Warner-Lambert } \\
\text { Company }\end{array}$ \\
\hline $\begin{array}{l}\text { Mohammed; } \\
\text { Monserrate, } \\
(1970) \\
\text { (Porto Rico) }\end{array}$ & $\begin{array}{l}\text { Ensaio clínico } \\
\text { aleatorizado } \\
\text { paralelo }\end{array}$ & $\begin{array}{l}40 \\
\text { Idade e sexo não } \\
\text { reportados }\end{array}$ & $\begin{array}{l}\text { Uso de alta rotação } \\
\text { para realização de } \\
\text { preparos cavitários } \\
\text { durante um minuto }\end{array}$ & $\begin{array}{l}\text { Um precipitador estéril foi } \\
\text { montado na posição } \\
\text { vertical e a extremidade do } \\
\text { adaptador de um tubo } \\
\text { estéril de coleta foi } \\
\text { conectada a um sugador à } \\
\text { vácuo. O ar coletado foi } \\
\text { sugado para dentro do } \\
\text { precipitador. }\end{array}$ & $\begin{array}{l}\text { Contagem do número } \\
\text { total de colônias } \\
\text { bacterianas }\end{array}$ & $\begin{array}{l}\text { Não houve } \\
\text { finaciamento }\end{array}$ \\
\hline
\end{tabular}

RCT = ensaio clinico randomizado, CFU =unidade formadoras de colônia, TSA = placas de agar soja 



\subsection{RISCO DE VIÉS}

Apenas um estudo (Retamal-Valdes et al., 2017) relatou o cálculo do tamanho da amostra. Os estudos de Retamal-Valdes et al. (2017), Shetty et al. (2013), Fine et al., estudo 1 (1993a), Fine et al., estudo 2 (1993a), Fine et al. (1993b) e Fine et al. (1992) relataram o método da geração de sequência aleatória (sequência gerada por computador). Nenhum estudo relatou adequadamente o sigilo de alocação. Em relação ao cegamento dos participantes, apenas os estudos realizados pelo grupo do pesquisador Fine usaram placebo ( $5 \%$ de hidroalcool). Outros estudos usaram como controle enxaguatório com água (Logothetis; MartinezWelles., 1995; Feres et al., 2010; Retamal-Valdes-Valdez et al., 2017; Dawson et al., 2016), não utilizaram nenhum enxágue (Mohammed; Monserrate,1970) ou não relataram adequadamente o tipo de controle usado (Gupta et al., 2014, Klyn et al., 2001; Shetty et al., 2013), sendo classificados como risco incerto de viés. A maioria dos estudos relatou cegamento do avaliador de desfecho, com exceção dos estudos realizados por Dawson et al. (2016), Klyn et al. (2001), Mohammed e Monserrate, (1970) e Shetty et al. (2013). O cegamento do operador foi considerado adequado nos seguintes estudos: Feres et al., 2010, Fine et al., 1993 a, Fine et al., 1993b, Fine et e Fine et al., 1992, Gupta. et al. (2014) e RetamalValdes et al. (2017).

No geral, cinco estudos foram classificados como alto risco de viés (Feres et al., 2010, Logothetis; Martinez-Welles, 1995, Mohammed; Monserrate 1970; Retamal- Valdes et al., 2017; Dawson et al., 2016) e sete estudos foram julgados como tendo risco de viés incerto (Fine et al., estudo 1 (1993a), Fine et al., estudo 2 (1993a), Fine et al. (1993b) e Fine et al. (1992); Gupta et al. (2014), Shetty et al. ., 2013, Klyn et al., 2001). 
Figura 5.2 - Risco de viés dos estudos incluídos

\begin{tabular}{|c|c|c|c|c|c|c|c|c|c|}
\hline & 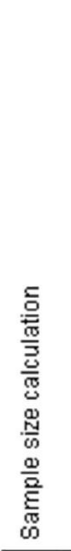 & 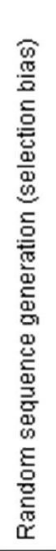 & 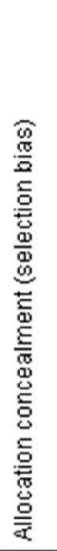 & 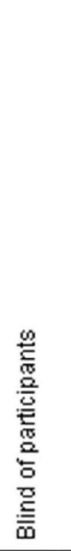 & 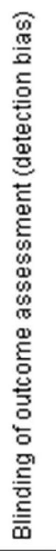 & 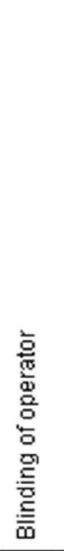 & 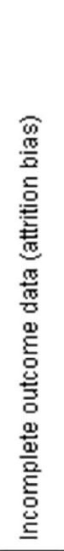 & 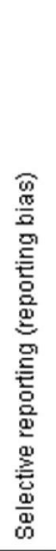 & 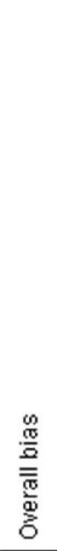 \\
\hline Dawson et al. 2016 & $?$ & $\odot$ & $?$ & $\odot$ & $?$ & $?$ & $\odot$ & $\odot$ & 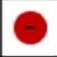 \\
\hline Feres et al. 2010 & $?$ & $?$ & $?$ & $\odot$ & $\odot$ & $\odot$ & $\odot$ & $\odot$ & $\theta$ \\
\hline Fine 1993a study 1 & $?$ & $\odot$ & $?$ & $\odot$ & $\odot$ & $\odot$ & + & $\odot$ & $?$ \\
\hline Fine 1993a study 2 & $?$ & $\odot$ & $?$ & $\bullet$ & $\odot$ & $\odot$ & $\bullet$ & $\odot$ & $?$ \\
\hline Fine 1993b & $?$ & $\odot$ & $?$ & 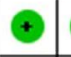 & $\odot$ & $\odot$ & $\odot$ & $\odot$ & $?$ \\
\hline Fine et al. 1992 & $?$ & $\odot$ & $?$ & $\odot$ & $\odot$ & $\odot$ & $\odot$ & $\odot$ & $?$ \\
\hline Gupta et al. 2014 & $?$ & $?$ & $?$ & $?$ & $\odot$ & $\odot$ & $\odot$ & $\odot$ & $?$ \\
\hline Klyn et al. 2001 & $?$ & $?$ & $?$ & $?$ & $?$ & $?$ & $\odot$ & $\odot$ & $?$ \\
\hline Logthetis et al. 1995 & $?$ & $?$ & $?$ & $\odot$ & $\odot$ & ○ & $\odot$ & $\odot$ & 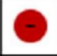 \\
\hline Mohamed et al. 1970 & $?$ & $?$ & $?$ & ○ & $?$ & $?$ & + & $\odot$ & $\theta$ \\
\hline Retamal-Valdez et al. 2016 & $\odot$ & $\odot$ & $\odot$ & $\theta$ & $\odot$ & $\odot$ & $\odot$ & $\odot$ & $\theta$ \\
\hline Shetty et al. 2013 & $?$ & $\odot$ & $?$ & $?$ & $?$ & $?$ & $\odot$ & $\odot$ & $?$ \\
\hline
\end{tabular}

Legenda:

Risco baixo de viés.

? Risco incerto de viés.

Alto risco de viés.

\subsection{RESULTADOS INDIVIDUAIS DOS ESTUDOS}

Os resultados individuais dos estudos incluídos são mostrados na Tabela 5.2 Em todos os estudos de Fine e colaboradores, os participantes apresentaram periodontite crônica, definida pela American Dental Association. Gupta et al. (2014) também selecionou pacientes com periodontite, definidos como aqueles que apresentavam quatro ou mais sítios com bolsas maiores ou iguais a $4 \mathrm{~mm}$. 
Os demais estudos incluíram pacientes saudáveis ou com gengivite (RetamalValdes Et al.,2017, Feres et al., 2010, Klyn et al.,2001, Mohammed; Monserrate et al 1970 e Dawson et al 2016). Nos estudos de Logothetis; Martinez-Welles (1995) e Shetty et al. (2013) a condição periodontal dos participantes não foi especificada.

A clorexidina ( $\mathrm{CHX}$ ) foi utilizada como enxaguatório pré-procedimento nos seguintes estudos: Retamal-Valdes et al. (2017), Gupta et al. (2014), Shetty et al. (2013), Feres et al. (2010), Klyin et al. (2001), Logothetis; Martinez-Welles (1995) e Dawson et al. (2016). Em todos estes estudos, o uso de bochecho com clorexidina reduziu significativamente o número de UFCs no consultório odontológico quando comparado ao placebo. No entanto, Dawson et al. (2016) observou que o uso de um enxágue bucal pré-procedimento, tanto com água estéril quanto com clorexidina $(\mathrm{CHX})$, aumentou o número de bactérias quando comparado a nenhum enxágue. Retamal- Valdes et al. (2017), Feres et al. (2010) e Mohammed; Monserrate, (1970) verificaram que o enxágue com solução de CPC reduziu significativamente 0 número de microrganismos. Todos os estudos que avaliaram bochechos com óleos essenciais (Fine et al., 1993a estudo 1, Fine et al., 1993a estudo 2, Fine et al., 1993b; Fine et al., 1992; Loghothetis; Martinez Welles,1995) relataram redução significativa no número de unidades formadoras de colônias após o enxágue com o produto.

Gupta et al. (2014) testou a clorexidina (CHX) e um produto fitoterápico como enxaguantes pré-procedimento. Embora ambos os agentes tenham reduzido significativamente as UFCs quando comparados ao placebo, o bochecho com $\mathrm{CHX}$ foi mais efetivo que o produto com o fitoterápico. Da mesma forma, Shetty et al. (2013) observou que a CHX e um produto fitoterápico reduziram as UFCs, mas a clorexidina foi significativamente mais eficiente na redução de microrganismos. Logothetis e Martinez-Welles (1995) também demonstraram superioridade da CHX na redução de microrganismos, quando comparados aos óleos essenciais. RetamalValdes-Valdez et al. (2017) e Feres et al. (2010) mostraram que CPC e CHX foram igualmente eficazes na redução do número de UFCs e tiveram melhor desempenho que a água e nenhum enxágue. No geral, exceto pelo estudo de Dawson et al. (2016), todas as investigações mostraram que o uso de enxaguatório bucal préprocedimento reduz significativamente o número de unidades formadoras de colônia (UFC), diminuindo assim o risco de infecção cruzada dentro do consultório odontológico. 
Tabela 5.2: Participantes, intervenção, resultados e conclusão

\begin{tabular}{|c|c|c|c|c|}
\hline Estudo & Tipo de participante & Intervenção & $\begin{array}{l}\text { Percentagem média de redução } \\
\text { de CFUs em comparação ao } \\
\text { controle }\end{array}$ & Conclusão do autor \\
\hline $\begin{array}{l}\text { Retamal Valdez et al. } \\
(2017) \\
\text { (Brasil) }\end{array}$ & $\begin{array}{l}\text { Pelo menos } 80 \% \text { dos locais } \\
\text { com placa supragengival } \\
\text { visível, menos de } 10 \% \text { dos } \\
\text { locais com cálculo } \\
\text { supragengival visível, } \\
\text { menos de } 30 \% \text { dos locais } \\
\text { com PD } \geq 5 \mathrm{~mm} \text {. }\end{array}$ & $\begin{array}{l}\text { 1) } 0.075 \% \mathrm{CPC}, 0.28 \% \mathrm{Zn} \\
\text { lactate and } 0.05 \% \mathrm{~F}, \mathrm{n}=15 \text {; } \\
\text { 2) } 0.12 \% \mathrm{CHX}, \mathrm{n}=15 ; \\
\text { 3) Água, } \mathrm{n}=15 ; \\
\text { 4) Sem bochecho, } \mathrm{n}=15\end{array}$ & $\begin{array}{l}\mathrm{CHX} \text { versus água }=70 \% * ; \mathrm{CXH} \\
\text { versus sem bochecho }=77 \%{ }^{*} ; \\
\mathrm{CPC} \text { versus água }=61 \%{ }^{*} ; \mathrm{CPC} \\
\text { versus sem bochecho }=70 \%{ }^{*}\end{array}$ & $\begin{array}{l}\text { O enxaguatório bucal pré- } \\
\text { procedimento contendo } 0,075 \% \\
\text { de CPC, } 0,28 \% \text { de lactato de } Z n \\
\text { e } 0,05 \% \text { de fluoreto de sódio foi } \\
\text { eficaz na redução de espécies } \\
\text { bacterianas presentes em } \\
\text { aerossóis durante a profilaxia } \\
\text { com instrumentos ultrassônicos }\end{array}$ \\
\hline $\begin{array}{l}\text { Dawson et al. (2016) } \\
\text { (Reino Unido) }\end{array}$ & $\begin{array}{l}\text { Pacientes que receberam } \\
\text { tratamento com aparelho } \\
\text { fixo e estavam programados } \\
\text { para a remoção dos } \\
\text { aparelhos. }\end{array}$ & $\begin{array}{l}\text { 1) Sem bochecho, } n=6 \text {; } \\
\text { 2) } 0.2 \% \mathrm{CHX}, \mathrm{n}=6 \text {; }\end{array}$ & $\begin{array}{l}\mathrm{CXH} \text { versus sem bochecho = } \\
\text { aumento de } 77 \% \\
\mathrm{CHX} \text { versus água= aumento de } \\
25,3 \%\end{array}$ & $\begin{array}{l}\text { O uso de água pré-procedimento } \\
\text { ou enxágue com } \mathrm{CHX} \text { pareceu } \\
\text { causar aumento no número e } \\
\text { diversidade de bactérias no ar. }\end{array}$ \\
\hline $\begin{array}{l}\text { Gupta et al. (2014) } \\
\text { (India) }\end{array}$ & $\begin{array}{l}\text { Escore médio da placa de } \\
2,0 \text { a } 3,0 \text { no índice de placa } \\
\text { (IP) e periodontite (quatro } \\
\text { ou mais locais com PD } \geq 4 \\
\mathrm{~mm} \text { ) }\end{array}$ & $\begin{array}{l}\text { 1) } 0.2 \% \mathrm{CHX}, \mathrm{n}=08 \text {; } \\
\text { 2) Herbal, } n=08 \text {; } \\
\text { 3) Água, } n=08\end{array}$ & $\begin{array}{l}\mathrm{CHX} \text { Versus água }=72,05 \% \text { * } \\
\text { fitoterápico versus água } \\
=35,86 \%{ }^{*}\end{array}$ & $\begin{array}{l}\text { O enxaguatório à base de ervas } \\
\text { foi eficaz na redução da } \\
\text { contaminação por aerossóis } \\
\text { produzida por raspagem com } \\
\text { ultrassom, embora menos } \\
\text { potente que a } \mathrm{CHX} \text { a } 0,2 \% \text {. }\end{array}$ \\
\hline $\begin{array}{l}\text { Shetty et al. (2013) } \\
\text { (India) }\end{array}$ & $\begin{array}{l}\text { Mínimo de } 20 \text { dentes } \\
\text { permanentes, Índice de }\end{array}$ & $\begin{array}{l}\text { 1) água destilada, } n=20 \text {; } \\
\text { 2) } 0.2 \% \mathrm{CHX}, \mathrm{n}=20 \text {; }\end{array}$ & $\mathrm{CHX}$ versus água $=93,3 \%$ * & $\begin{array}{l}\text { Todos os antissépticos } \\
\text { reduziram as } \quad \text { CFU bacterianas }\end{array}$ \\
\hline
\end{tabular}




\begin{tabular}{|c|c|c|c|c|}
\hline & $\begin{array}{l}\text { higiene bucal entre } 1,3 \text { e } 3 \text {, } \\
\text { Índice de placa entre } 1 \text { e } 2\end{array}$ & 3) fitoterápico $n=20$ & & $\begin{array}{l}\text { nas amostras de aerossóis. Os } \\
\text { bochechos com } \mathrm{CHX} \text { foram } \\
\text { considerados superiores. }\end{array}$ \\
\hline $\begin{array}{l}\text { Feres et al. (2010) } \\
\text { (Brazil) }\end{array}$ & $\begin{array}{l}\text { Em } 20 \text { dentes naturais, } 80 \\
\text { por cento das superfícies } \\
\text { dos dentes tinham placa } \\
\text { supra gengival visível, } \\
\text { menos de } 10 \text { por cento } \\
\text { tinham um cálculo supra } \\
\text { gengival visível e menos de } \\
30 \text { por cento tinham PD e } \\
\text { CAL } \geq 5 \text { mm }\end{array}$ & $\begin{array}{l}\text { 1) Água, } n=15 \text {; } \\
\text { 2) sem bochecho, } n=15 \text {; } \\
\text { 3) } 0.12 \% \mathrm{CHX}, \mathrm{n}=15 \\
\text { 4) } 0.05 \% \mathrm{CPC}, \mathrm{n}=15\end{array}$ & $\begin{array}{l}\text { CPC versos controle }=68 \% * \\
\mathrm{CHX} \text { versos controle }=70 \% *\end{array}$ & $\begin{array}{l}\text { Os enxaguatórios bucais } \\
\text { contendo } 0,05 \% \text { de } \mathrm{CPC} \text { e } \\
0,12 \% \text { de } \mathrm{CHX} \text { são igualmente } \\
\text { eficazes na redução dos níveis } \\
\text { de bactérias geradas durante a } \\
\text { raspagem ultrassônica. }\end{array}$ \\
\hline Klyn et al. (2001) & $\begin{array}{l}\text { ADA tipo periodontal I } \\
\text { (gengivite) oul (periodontite } \\
\text { incipiente), conforme } \\
\text { determinado pelo exame } \\
\text { clínico e radiografia. }\end{array}$ & $\begin{array}{l}\text { 1) Sem bochecho, } n=15 \\
\text { 2) } 0.12 \% \mathrm{CHX}, n=15\end{array}$ & CPC versos controle $=51,43 \%$ * & $\begin{array}{l}\text { O enxágue } \mathrm{CHX} \text { pré-operatório } \\
\text { reduz a disseminação do } \\
\text { aerossol contendo bactérias } \\
\text { durante a raspagem com } \\
\text { ultrasson }\end{array}$ \\
\hline $\begin{array}{l}\text { Logothetis, Martinez- } \\
\text { Welles (1995) } \\
\text { (EUA) }\end{array}$ & $\begin{array}{l}20 \text { dentes permanentes e } \\
\text { um escore médio de placa } \\
\text { de } 1,8 \text { a } 3,0 \text { no Índice de } \\
\text { Placa }\end{array}$ & $\begin{array}{l}\text { 1) água, } n=6 \text {; } \\
\text { 2) } 0.12 \% \mathrm{CHX}, \mathrm{n}=6 \text {; } \\
\text { 3) Óleos essenciais, } n=6\end{array}$ & $\begin{array}{l}\text { CHX versus controle }= \\
92,32 \% * ; \\
\text { Óleos essenciais versus } \\
\text { controle }=10,01 \%\end{array}$ & $\begin{array}{l}\text { Bochechos pré-procedimentos } \\
\text { com } \mathrm{CHX} \text { podem eliminar a } \\
\text { maioria dos microrganismos } \\
\text { gerados pelo uso do dispositivo } \\
\text { de polimento, fornecendo }\end{array}$ \\
\hline
\end{tabular}




\begin{tabular}{|c|c|c|c|c|}
\hline & & & & $\begin{array}{l}\text { proteção de até } 9 \text { pés do centro } \\
\text { da operação. }\end{array}$ \\
\hline $\begin{array}{l}\text { Fine et al. (1993 a) } \\
\text { estudo } 1 \\
\text { (EUA) }\end{array}$ & $\begin{array}{l}\text { ADA Tipo Periodontal Tipo I } \\
\text { (gengivite) ou II } \\
\text { (periodontite incipiente), } \\
\text { conforme determinado pelo } \\
\text { exame clínico e radiografia; } \\
\text { presença de pelo menos } 20 \\
\text { dentes naturais sadios com } \\
\text { índice médio de placa> 1,5 } \\
\text { e índice gengival médio> } \\
1,5\end{array}$ & $\begin{array}{l}\text { 1) Óleos essenciais, } n=18 \text {; } \\
\text { 2) Placebo ( } 5 \% \\
\text { Hydroalcohol), } \\
n=18\end{array}$ & $\begin{array}{l}\text { Óleos essenciais } \\
\text { Versus } \\
\text { controle }=91,1 \% \text { * }\end{array}$ & $\begin{array}{l}\text { Os estudos (Fine et al., 1993a e } \\
\text { Fine et al., 1993b) sugerem que } \\
\text { o enxágue pré-procedimento } \\
\text { com óleos essencial pode } \\
\text { potencialmente reduzir o risco de } \\
\text { contaminação cruzada com } \\
\text { agentes infecciosos em cirurgia } \\
\text { dentária. }\end{array}$ \\
\hline $\begin{array}{l}\text { Fine et al. (1993a) } \\
\text { estudo } 2 \\
\text { (EUA) }\end{array}$ & $\begin{array}{l}\text { ADA Tipo Periodontal Tipo I } \\
\text { (gengivite) ou II } \\
\text { (periodontite incipiente), } \\
\text { conforme determinado pelo } \\
\text { exame clínico e radiografia; } \\
\text { presença de pelo menos } 20 \\
\text { dentes naturais sadios com } \\
\text { índice médio de placa> 1,5 } \\
\text { e índice gengival médio> } \\
1,5\end{array}$ & $\begin{array}{l}\text { 1) Óleos essenciais, } n=18 \\
\text { 2) Placebo ( } 5 \% \text { Hydroalcohol), } \\
n=18\end{array}$ & $\begin{array}{l}\text { 1)Óleos essenciais } \\
\text { versus } \\
\text { controle }=89,82 \% \text { * }\end{array}$ & $\begin{array}{l}\text { Os estudos (Fine et al., 1993a e } \\
\text { Fine et al., 1993b) sugerem que } \\
\text { o enxágue pré-procedimento } \\
\text { com óleos essencial pode } \\
\text { potencialmente reduzir o risco de } \\
\text { contaminação cruzada com } \\
\text { agentes infecciosos em cirurgia } \\
\text { dentária. }\end{array}$ \\
\hline $\begin{array}{l}\text { Fine et al. (1993 b) } \\
\text { (EUA) }\end{array}$ & $\begin{array}{l}\text { ADA Tipo Periodontal Tipo I } \\
\text { (gengivite) ou II periodontite } \\
\text { incipiente), conforme } \\
\text { determinado pelo }\end{array}$ & $\begin{array}{l}\text { 1) Óleos essenciais, } n=18 ; \\
\text { 2)Placebo(5\% Hydroalcohol), } \\
n=18\end{array}$ & $\begin{array}{l}\text { Óleos essenciais } \\
\text { versus } \\
\text { controle }=90,59 \% \text { * }\end{array}$ & $\begin{array}{l}\text { Bochechos com antisséptico no } \\
\text { início de uma visita odontológica } \\
\text { reduzem significativamente o } \\
\text { nível de bactérias viáveis em um }\end{array}$ \\
\hline
\end{tabular}




\begin{tabular}{|c|c|c|c|c|}
\hline & $\begin{array}{l}\text { exame clínico e radiografia; } \\
\text { presença de pelo menos } 20 \\
\text { dentes naturais sadios com } \\
\text { índice médio de placa> } 1,5 \\
\text { e índice gengival médio> } \\
1,5\end{array}$ & & & $\begin{array}{l}\text { aerossol produzida por } \\
\text { raspagem com ultrassom }\end{array}$ \\
\hline $\begin{array}{l}\text { Fine et al. } 1992 \\
\text { (EUA) }\end{array}$ & $\begin{array}{l}\text { ADA Tipo Periodontal Tipo I } \\
\text { (gengivite) ou II periodontite } \\
\text { incipiente) conforme } \\
\text { determinado pelo exame } \\
\text { clínico e radiografia; } \\
\text { presença de pelo menos } 20 \\
\text { dentes naturais sadios com } \\
\text { índice médio de placa> 1,5 } \\
\text { e índice gengival médio> } \\
\text { 1,5. }\end{array}$ & $\begin{array}{l}\text { 1) Óleos essenciais, } n=18 ; \\
\text { 2)Placebo(5\% Hydroalcohol), } \\
n=18\end{array}$ & $\begin{array}{l}\text { Óleos essenciais } \\
\text { Versus } \\
\text { controle }=39,92 \%{ }^{*}\end{array}$ & $\begin{array}{l}\text { O antisséptico bucal usado } \\
\text { como enxágue pré-procedimento } \\
\text { pode reduzir significativamente o } \\
\text { conteúdo microbiano viável de } \\
\text { aerossóis gerados durante } \\
\text { procedimentos odontológicos }\end{array}$ \\
\hline $\begin{array}{l}\text { Mohammed; Monserrate, } \\
1970 \\
\text { (Porto Rico) }\end{array}$ & $\begin{array}{l}\text { Os pacientes utilizados } \\
\text { neste estudo tinham } \\
\text { gengivite moderada }\end{array}$ & $\begin{array}{l}\text { 1) } C P C, n=20 \text {; } \\
\text { 2) Sem bochecho, } n=20\end{array}$ & $\begin{array}{l}\text { CPC } \\
\text { versus } \\
\text { controle }=56.7 \% *\end{array}$ & $\begin{array}{l}\text { A formulação de bochecho } \\
\text { usada neste estudo pareceu } \\
\text { reduzir significativamente a } \\
\text { contaminação produzida durante } \\
\text { o uso de peças de mão. }\end{array}$ \\
\hline
\end{tabular}

* redução significante quando comparada ao controle; $\mathrm{CPC}=$ cloreto de cetil; $\mathrm{CHX}=$ clorexidina; $\mathrm{ZN}$ - zinco; $\mathrm{PI}=$ indice de placa, $\mathrm{PD}=$ profundidade de sondagem 


\subsection{META-ANÁLISE}

Apenas os quatro estudos do grupo de Fine colaboradores (Fine et al., 1992; Fine et al., 1993a estudo 1, Fine et al., 1993a estudo 2, Fine et al., 1993b) apresentaram dados de UFC antes e depois do uso de enxaguatórios bucais. Consequentemente, apenas estes estudos foram incluídos na metanálise.

Os resultados combinados da metanálise da eficácia do enxaguatório bucal com óleos essenciais sugerem redução significativa do número de UFCs (diferença média de 73,9\%; IC 95\% 40,8\% - 107,1\%, I²= 72\%) quando comparados ao enxágue com placebo.

Figura 5.3 - Forest plot de redução percentual de unidades formadoras de colônia

\begin{tabular}{|c|c|c|c|c|c|c|}
\hline Study or Subgroup & Mean Difference & SE & Weight & $\begin{array}{l}\text { Mean Difference } \\
\text { IV, Random, } 95 \% \mathrm{Cl}\end{array}$ & $\begin{array}{l}\text { Mean Diffe } \\
\text { IV, Random }\end{array}$ & $\begin{array}{l}\text { ference } \\
\mathrm{n}, \mathbf{9 5} \% \mathrm{Cl}\end{array}$ \\
\hline \multicolumn{7}{|c|}{ 1.1.3 Essential oils vs Control } \\
\hline Fine 1993a study 1 & 91.1 & 21.89 & $22.4 \%$ & $91.10[48.20,134.00]$ & & \\
\hline Fine 1993a study 2 & 89.82 & 21.53 & $22.7 \%$ & $89.82[47.62,132.02]$ & & \\
\hline Fine 1993b & 90.59 & 21.72 & $22.6 \%$ & $90.59[48.02,133.16]$ & & \\
\hline $\begin{array}{l}\text { Fine et al. } 1992 \\
\text { Subtotal }(95 \% \mathrm{Cl})\end{array}$ & 39.22 & 9.4 & $\begin{array}{r}32.3 \% \\
100.0 \%\end{array}$ & $\begin{array}{r}39.22[20.80,57.64] \\
73.93[40.77, \mathbf{1 0 7 . 0 8}\end{array}$ & & \\
\hline \multicolumn{7}{|c|}{$\begin{array}{l}\text { Heterogeneity: } \operatorname{Tau}^{2}=797.19 ; \mathrm{Ch}^{2}=10.71, \mathrm{df}=3(\mathrm{P}=0.01) ; \mathrm{I}^{2}=72 \% \\
\text { Test for averall effect: } Z=4.37(P<0.0001)\end{array}$} \\
\hline Total $(95 \% \mathrm{Cl})$ & & & $100.0 \%$ & $73.93[40.77,107.08]$ & & \\
\hline \multicolumn{5}{|c|}{$\begin{array}{l}\text { Heterogeneity: } \text { Tau }^{2}=797.19 ; \mathrm{Ch}^{2}=10.71, \mathrm{df}=3(\mathrm{P}=0.01) ; \mathrm{I}^{2}=72 \% \\
\text { Test for averall effect: } Z=4.37(P<0.0001)\end{array}$} & $\begin{array}{ccc}-100 & -50 & 0 \\
\text { Favours [Control rinse] }\end{array}$ & $\begin{array}{cc}50 & 100 \\
\text { Favours [Test rinse] }\end{array}$ \\
\hline
\end{tabular}




\section{DISCUSSÃO}

Os resultados desta revisão fornecem evidência sobre a eficácia dos enxaguatórios bucais pré-procedimento na redução do número de bactérias disseminadas pelo aerosol após diferentes procedimentos odontológicos. Essa eficácia foi demonstrada pela capacidade destes enxaguatórios em diminuir o número de microrganismos isolados em placas de ágar espalhadas em vários pontos no consultório odontológico, bem como em filtros estéreis ligados os dispositivos de coleta de ar a vácuo. Os resultados desta revisão são importantes, uma vez que uma redução no número de bactérias aerolisadas pode reduzir o risco de contaminação cruzada no consultório odontológico, ajudando a proteger os dentistas e pacientes.

Embora o uso de equipamentos de proteção individual e outras medidas de controle de infecção sejam práticas comuns entre os dentistas, eles apresentam limitações. Por exemplo, a maioria das máscaras cirúrgicas não protege completamente contra a exposição a microrganismos aerolisados, devido à presença de pequenas aberturas ou defeitos nestas (CDC, 2003). Na mesma linha de raciocínio, as luvas podem ter pequenos defeitos e podem se rasgar durante 0 seu uso (CDC, 2003). Além disso, microrganismos aerolisados permanecem suspensos no consultório odontológico por até 4 horas após um procedimento odontológico (Grenier, 1995), de modo que os dentistas e auxiliares podem ficar expostos ao remover o equipamento de proteção entre as consultas. Consequentemente, uma redução nos níveis de microrganismos no aerossol promove proteção adicional contra a contaminação cruzada no ambiente odontológico.

Até onde sabemos, este é o primeiro estudo que revisou sistematicamente a eficácia dos enxaguatórios bucais pré-procedimento na redução de bactérias no aerossol dental. Consequentemente, não foi possível comparar nossos resultados com revisões anteriores. Todos os princípios ativos incluídos nesta revisão (i.e., clorexidina, óleos essenciais, cloreto de cetilperidínio e produtos fitoterápicos) reduziram significativamente o número de micro-organismos no aerossol, quando comparados com o placebo. Surpreendentemente, um estudo (Dawson et al., 2016) observou que o número de bactérias aumentou após o uso de um enxaguatório 
Bucal pré-procedimento (água ou clorexidina). Como a maioria dos estudos não possuía dados pré-enxaguatórios, não foi possível realizar metanálise para esses estudos. Assim, não é possível comparar a eficácia de diferentes enxaguatórios bucais. Na análise de estudos individuais, dois estudos (Feres et al., 2010 e Retamal et al., 2017) revelaram que não houve diferenças significativas entre $\mathrm{CHX}$ e CPC na redução de UFC. Por outro lado, Logothetis e Martinez-Welles (1995) observaram que a $\mathrm{CHX}$ promoveu uma redução significativamente maior nas bactérias aerolisadas do que os OEs. Da mesma forma, $\mathrm{CHX}$ foi superior aos enxaguatórios herbais em dois estudos (Gupta et al., 2014; Shetty et al., 2013).

Os resultados desta revisão devem ser avaliados com cautela. Em primeiro lugar, é importante observar que o desfecho primário de todos os estudos (isto é, a redução do número de microrganismos aerolisados) é um desfecho substituto da contaminação cruzada no consultório odontológico. Embora os enxaguatórios bucais pré-procedimentos reduzam significativamente os níveis de contaminação do ar no consultório odontológico, a influência dessa diminuição nas taxas de infecção é desconhecida. Não há evidência direta que o uso de enxaguatórios bucais préprocedimento reduzam a incidência de doenças infectocontagiosas no consultório odontológico. Para um estudo deste tipo, seriam necessárias centenas de pacientes em cada braço do estudo, bem como muitos anos de acompanhamento.

Além disso, nenhum estudo incluído nesta revisão apresentou baixo risco de viés. Cinco estudos apresentaram alto risco de viés (Mohammed; Monserrate et al., 1970; Logothetis; Martinez-Welles,1995; Feres et al., 2010; Dawson et al., 2016; Retamal-Valdez et al., 2017) e sete apresentaram risco incerto de viés (Fine et al., 1992; Fine et al., 1993a estudo 1; Fine et al., 1993a estudo 2; Fine et al., 1993b; Gupta et al., 2014; Klyn et al., 2001; Shetty et al., 2013). Nenhum dos estudos relatou adequadamente a sigilo de alocação, o que pode resultar em superestimação do efeito da intervenção (Schulz \& Grimes, 2002; Savovic et al., 2012). Da mesma forma, o cegamento dos participantes foi considerado adequado apenas nos estudos do grupo de Fine e colaboradores, que utilizaram um enxaguatório placebo com hidroálcool a 5\%. Assim, estudos futuros devem tentar minimizar as fontes de viés, por exemplo, com o uso de enxaguatório bucal placebo e implementação de algum método de sigilo de alocação (por exemplo, uso de envelopes opacos, lacrados e numerados sequencialmente). 


\section{CONCLUSÃO}

O uso de enxaguatório pré-procedimento reduz o número de bactérias no aerossol gerado por procedimentos odontológicos. 


\section{REFERÊNCIAS ${ }^{1}$}

Almerich JM, Cabedo B, Ortolá JC, Poblet J.Influence of alcohol in mouthwashes containing triclosan and zinc: an experimental gingivitis study. J Clin Periodontol.2005 Jun;32(6):539-44.doi:10.1111/j.1600-051X.2005.00675.x

Ansaldi F, Orsi A, Sticchi L, Bruzzone B, Icardi G Hepatitis C virus in the new era: perspectives in epidemiology, prevention, diagnostics and predictors of response to therapy. World J Gastroenterol. 2014 Aug 7;20(29):9633-52. doi: 10.3748/wjg.v20.i29.9633.

Bambace A. M. J. Eficácia de soluções aquosas de clorexidina para a desinfecção de superfícies. Rev. Biociênc. 2003(9):73-81

Barker J, Jones MV. The potential spread of infection caused by aerosol contamination of surfaces after flushing a domestic toilet. JAppl Microbiol. 2005; 99(2):339-347. doi:10.1111/j.1365-2672.2005.02610.x

Bell D.M. Occupational risk of human immunodeficiency virus infection in health care workers: an overwiew. Am J Med.1997; 102(5B):9-15.

Browning WD, McCarthy JP. A case series: Herpes simplex virus as an occupational hazard. J Esthet Restor Dent. 2012: 61 doi: 10.1111/j.17088240.2011.00469.x.

Burgard, Leão. Controle de infecção em Odontologia. Curitiba: Champagnat, 1997.

CDC Center for Disease Control and Prevention. Recommended Infection Control Practices for Dentistry. MMWR 1986;35:237-42.

CDC. Guidelines for environmental infection control in health-carefacilities: recommendations of CDC and the Healthcare InfectionControl Practices Advisory Committee (HICPAC). MMWR 2003; 52

Chambrone L, Faggion CM Jr., Pannuti CM, Chambrone LA. Evidencebasedperiodontal plastic surgery: An assessment of quality of systematic reviews 
in the treatment of recession-type defects. J Clin Periodontol. 2010;37: 11101118. doi: 10.1111/j.1600-051X.2010.01634.x.

Charles $\mathrm{CH}$, Pan PC, Sturdivant L, Vincent JW.In vivo antimicrobial activity of an essential oil-containing mouthrinse on interproximal plaque bacteria. J Clin Dent. 2000;11(4):94-7

Cortelli SC, Cortelli JR, Shang H, Costa R, Charles CA. Gingival health benefits of essential-oil and cetylpyridinium chloride mouthrinses: a 6-month randomized clinical study. Am J Dent. 2014; 27(3):119-26.

Cottone J.A.,Terezhalmy GT,Molinari JA. Practical infection control in dentistry. Baltimore: Willians \& Wilkins, 1996.

Cottone JA, Molinari JA. State-of-the-art infection control in dentistry. J Am Dent Assoc. 1991 Aug;122(8):33-41.

Cowan M M.Plant Products as Antimicrobial Agents. Clin Microbiol Rev. 1999 Oct; 12(4): 564-82

Cowling BJ, Ip DK, Fang VJ, Suntarattiwong P, Olsen SJ, Levy J, et al.Aerosol transmission is an important mode of influenza A virus spread. Nat Commun. 2013(4):19-35.

Dawson M, Soro V, Dymock D, Price R Griffiths H, Dudding T, Sandy JR, Ireland AJ.Microbiological assessment of aerosol generated during debond of fixed orthodontic appliances. Am J Orthod Dentofacial Orthop. 2016;150(5):831-38 doi:10.1016/j.ajodo.2016.04.022

Denton W. Chlorhexidine In: Sterilisation and Preservation 5th Edition, Block SS, eds. Lippincott Williams \& Williams, Philadelphia; 2001:321-36.

Department of Labor; Occupational Safety and Health Administration. Occupational exposure to bloodborne pathogens; Proposed rule and notice of hearing. Fed Reg.1989;54:23134-9.

Devker NR, Mohitey J, Vibhute A, Chouhan VS, Chavan P, Malagi S, Joseph RJ. A study to evaluate and compare the efficacy of preprocedural mouthrinsing and high volume evacuator attachment alone and in combination in reducing the 
amount of viable aerosols produced during ultrasonic scaling procedure. $\mathrm{J}$ Contemp Dent Pract. 2012; 13(5): 681-9.

Dunn. The efficacy of a pre-procedural antiseptic mouthwash against bacterial aerosols. J N Z Soc Periodontol. 1999;(84):21-3. doi:10.1590/1807-3107

Elworthy A, Greenman J, Doherty FM, Newcombe RG, Addy M . The substantivity of a number of oral hygiene products determined by the duration of effects on salivary bacteria. J Periodontol. 1996 Jun;67(6):572-6. doi:10.1902/jop.1996.67.6.572

Feres M, Figueiredo LC, Faveri M, Stewart B, de Vizio W.The effectiveness of a pre-procedural mouthrinse containing cetylpyridinium chloride in reducing bacteria in the dental office. J Am Dent Assoc. 2010 Apr;141(4):415-22.

Fine DH, Furgang D, Korik I,Olshan A, Barnett ML, Vincent JW.Reduction of viable bacteria in dental aerosols by preprocedural rinsing with an antiseptic mouthrinse. Am J Dent. 1993a;6(5):219-21.

Fine DH, Yip J, Furgang D, Barnett ML, Olshan AM, Vincent J.Reducing bacteria in dental aerosols: pre-procedural use of an antiseptic mouthrinse. J Am Dent Assoc. 1993b;124(5):56-8.

Fine DH, Mendieta C, Barnett ML, Furgang D, Meyers R, Olshan A, et al J.Efficacy of preprocedural rinsing with an antiseptic in reducing viable bacteria in dental aerosols. J Periodontol.1992;63(10):821-4.

Fine DH, Furgang D, Barnett ML, Drew C, Steinberg L, Charles CH, Vincent JW. Effect of an essential oil-containing antiseptic mouthrinse on plaque and salivary Streptococcus mutans levels. J Clin Periodontol. 2000 Mar;27(3):157-61.

García-Caballero L, Quintas V, Prada-López I, Seoane J, Donos N, Tomás I. Chlorhexidine substantivity on salivary flora and plaque-like biofilm: an in situ model. PLoS One. 2013 Dec 27;8(12):e83522. doi: 10.1371/journal.pone.0083522.

Gralton J, Tovey E, McLaws ML, Rawlinson WD. The role of particle size in aerosolised pathogen transmission: a review. J Infect. 2011; 62(1):1-13. doi: 10.1016/j.jinf.2010.11.010

Grenier D. Quantitative analysis of bacterial aerosols in two different dental clinic environments. Appl EnvironMicrobiol. 1995;61(8):3165-3168 
Gupta G, Mitra D, Ashok KP, Gupta A, Soni S, Ahmed S, Arya A.Efficacy of preprocedural mouth rinsing in reducing aerosol contamination produced by ultrasonic scaler: a pilot study. J Periodontol .2014;85(4):562-8.doi: 10.1902/jop.2013.120616

Gunson RN1, Shouval D, Roggendorf M, Zaaijer H, Nicholas H, Holzmann H et al.Hepatitis $B$ virus (HBV) and hepatitis $C$ virus (HCV) infections in health care workers (HCWs): guidelines for prevention of transmission of HBV and HCV from HCW to patients. J Clin Virol.2003; 27:213-30.

Haas AN, Wagner TP, Muniz FW, Fiorini T, Cavagni J, Celeste RK.Essential oilscontaining mouthwashes for gingivitis and plaque: Meta-analyses and metaregression. J Dent. 2016 Dec;55:7-15. doi: 10.1016/j.jdent.2016.09.001.

Haps S, Slot DE, Berchier CE, Van der Weijden GA.The effect ofcetylpyridinium chloride-containing mouth rinses as adjuncts to toothbrushing on plaque and parameters of gingival inflammation: a systematic review. Int J Dent Hyg. 2008 Nov;6(4):290-303. doi: 10.1111/j.1601-5037.2008.00344.x.

Higgins JPT, Green S. Cochrane Handbook for Systematic Reviews of Interventions. September 2011; version 5.0.1.[10 jun 2018]. Disponivel em: www.cochrane-handbook.org.

Husain M.Avian influenza A (H7N9) virus infection in humans: epidemiology, evolution, and pathogenesis. Infect Genet Evol. 2014. Dec;28:304-12. doi:10.1016/j.meegid.2014.10.016.

Hinds WC. Aerosol technology: properties, behavior, and measurement of airborneparticles. New York: Wiley; 1982.

Ippolito G1, Puro V, De Carli G .The risk of occupational human immunodeficiency virus infection in health care workers. Italian Multicenter Study. The Italian Study Group on Occupational Risk of HIV infection. Arch Intern Med. 1993 Jun 28;153(12):1451-8.

Jakubovics N,. Greenwood M, Meechan JP .General medicine and surgery for dental practitioners: part 4. Infections and infection control. Br Dent J. 2014 Jul;217(2):73-7. doi:10.1038/sj.bdj.2014.593. 
Kaur R, Singh I, Vandana KL, Desai R. Effect of chlorhexidine, povidone iodine, and ozone on microorganisms in dental aerosols: randomized double-blind clinical trial. Indian J Dent Res. 2014; 25(2):160-165. doi: 10.4103/09709290.135910.

Keijser JA1, Verkade H, Timmerman MF, Van der Weijden FA.Comparison of 2 commercially available chlorhexidine mouthrinses. J Periodontol. 2003 Feb;74(2):214-8. doi: 10.1902/jop.2003.74.2.214

Klyn SL, Cummings DE, Richardson BW, Davis RD.Reduction of bacteriacontaining spray produced during ultrasonic scaling. Gen Dent. 2001;(6):648-652.

Kurita $\mathrm{H}$, Kurashina $\mathrm{K}$, Honda T.Nosocomial transmission of methicillin-resistant Staphylococcus aureus via the surfaces of the dental operatory. Br Dent J. 2006 Sep 9;201(5):297-300

Larson EL. APIC guideline for hand washing and hand antisepsis in health-care settings. Am J Infect Control 1995;23:251-69.

Larson EL, Early E, Cloonan P, Sugrue S, Parides M. An organizational climate intervention associated with increased handwashing and decreased nosocomial infections. Behav Med 2000;26:14--22. doi: 10.1080/08964280009595749

Leggat PA, Kedjarune U. Bacterial aerosols in the dental clinic: a review. Int Dent J. 2001;51(1):39-44.

Logothetis, Martinez-Welles, Martinez-Welles, Martinez-Welles DD, MartinezWelles JM.Reducing bacterial aerosol contamination with a chlorhexidine gluconate pre-rinse. J Am Dent Assoc. 1995;126(12):1634-1639

Mccoy LC, Wehler CJ, Rich SE, Garcia RI, Miller DR, Jones JA. Adverse events associated with chlorhexidine use. J Am Dent Assoc. 2008;149(2):178-83.

Miller $\mathrm{CH}$.Cleaning, sterilization and disinfection: basics of microbial killing for infection control. J Am Dent Assoc. 1993 Jan;124(1):48-56.

Meiller, Silva, Ferreira, Jabra-Rizk, Kelley, DePaola .Efficacy of Listerine Antiseptic in reducing viral contamination of saliva. J Clin Periodontol. 2005. Apr;32(4):341-6. 
Moher, Shamseer , Clarke, et al; PRISMA-P Group. Preferred reporting items for systematic review and meta-analysis protocols (PRISMA-P) 2015 statement. Syst Rev 2015;4:1.

Mohammed Cl, Monserrate V.Preoperative oral rinsing as a means of reducing air contamination during use of air turbine handpieces. Oral Surg Oral Med Oral Pathol. 1970;29(2):291-4

Mouchrek, Nunes LH, Arruda CS, Rizzi Cde C, Mouchrek AQ, Tavarez RR, Tonetto MR, Bandeca MC.Effectiveness of Oral Antiseptics on Tooth Biofilm: A Study in vivo. J Contemp Dent Pract. 2015 Aug 1;16(8):674-8.

Muir KF, Ross PW, MacPhee IT, Holbrook WP, Kowolik MJ. Reduction of microbial contamination from ultrasonic scaleres. Br Dent J. 1978; 145(3): 76-78. doi: 10.7860/JCDR/2015/12038.5835

Nejatidanesh F, Khosravi Z, Goroohi H, Badrian H, Savabi O. Risk of contamination of different areas of dentist's face during dental practices. Int $\mathrm{J}$ Prev Med. 2013;4(5):611-5.

Okuda K, Adachi M, lijima K. The efficacy of antimicrobial mouth rinses in oral health care. Bull Tokyo Dent Coll. 1998 Feb;39(1):7-14.

O'Leary E, Lockhart D E, Smith A, Coming to a practice near you? Communityacquired meticillin resistant Staphylococcus aureus (CA-MRSA). Dent Update.2011; 38:254-6, 259-60. doi:10.12968/denu.2011.38.4.254

Ouhayoun JP.Penetrating the plaque biofilm: impact of essential oil mouthwash.J Clin Periodontol. 2003; 30 Suppl 5:10-2.

Pan P, Barnett ML, Coelho J, Brogdon C, Finnegan MB. Determination of the in situ bactericidal activity of an essential oil mouthrinse using a vital stain method. $J$ Clin Periodontol. 2000 Apr;27(4):256-61.

Pankhurst C L, Coulter, W A, Basic guide to infection prevention and control in dentistry. Chichester: Wiley-Blackwell;2009.

Plotkowski MC1, Bajolet-Laudinat O, Puchelle E Cellular and molecular mechanisms of bacterial adhesion to respiratory mucosa. Eur Respir J. 1993 Jun;6(6):903-16. 
Rautemaa R, Nordberg A, WuolijokiSaaristo K, MeurmanJH. Bacterial aerosols in dental practice - a potential hospital infection problem? J Hosp Infect. 2006 Sep;64(1):76-81. doi:10.1016/j.jhin.2006.04.011

Retamal-Valdes B, Soares GM, Stewart B, Figueiredo LC, Faveri M, Miller S, Zhang YP, Feres M.Effectiveness of a pre-procedural mouthwash in reducing bacteria in dental aerosols: randomized clinical trial. Braz Oral Res. 2017 Mar 3031. doi:10.1016/j.jhin.2006.04.011

Roberts M, Addy W.R. Comparison of the in vivo and in vitro antibacterial properties of antiseptic mouthrinses containing chlorhexidine, alexidine, cetyl pyridinium chloride and hexetidine, Relevance to mode of action.J Clin Periodontol, (8) 198: 295-310

Rösing CK, Cavagni J, Gaio EJ, Muniz FWMG, Ranzan N, Oballe HJR, Friedrich SA, Severo RM, Stewart B, Zhang YP Efficacy of two mouthwashes with cetylpyridinium chloride: a controlled randomized clinical trial Braz Oral Res. 2017 Jul 3;31:e47. doi: 10.1590/1807-3107

Santos IRM, Moreira ACA, Costa MGC, Barbosa MC. Effect of $0.12 \%$ chlorhexidine in reducing microorganisms found in aerosol used for dental prophylaxis of patients submitted to fixed orthodontic treatment. Dental Press J Orthod. 2014; 19(3): 95-101. doi: 10.1590/2176-9451.19.3.095-101

Savović J1, Jones HE, Altman DG, Harris RJ, Jüni P, Pildal J, Als-Nielsen B, Balk EM, Gluud C, Gluud LL, loannidis JP, Schulz KF, Beynon R, Welton NJ, Wood L, Moher D, Deeks JJ, Sterne JA. Influence of reported studydesign characteristics on intervention effect estimates from randomized, controlled trials. Ann Intern Med. 2012 Sep 18;157(6):429-38

Schulz KF, Grimes DA. Allocation concealment in randomized trials: defending against deciphering. Lancet (London, England).2002;359:614-8. doi:10.1016/S0140-6736(02)07750-4

Shetty SK, Sharath K, Shenoy S, Sreekumar C, Shetty RN, Biju T.Compare the effcacy of two commercially available mouthrinses in reducing viable bacterial count in dental aerosol produced during ultrasonic scaling when used as a preprocedural rinse.J Contemp Dent Pract. 2013;14(5):848-51 
Stirrups .Methods of reducing bacterial contamination of the atmosphere arising from use of an air-polisher'. Br Dent J. 1987 Oct 10;163(7):215-6.

Stokowski, L.A. 2011. MRSA in the dental office. Medscape Den tal and Oral Health, Apr 01, 2011. www.medscape.com/viewarticle/ 739763_4.

Suresh S, Manimegalai M, Sudhakar U, Sopia Comparison of efficacy of Preprocedural Rinsing with Chlorhexidine mouth rinse and essential oil containing mouth rinse. Int J of Cont Dentistry. 2011;2(6):1-6.

Szymańska J. Dental bioaerosol as an occupational hazard in a dentist's workplace. Ann Agric Environ Med. 2007;14(2):203-7

Thomas, M.V., G. Jarboe, and R.Q. Frazer. 2008. Infection control in the dental office. Dental Clin. North Am. 52:609-628. doi: 10.1016/j.cden.2008.02.002.

Timmerman MF, Menso L, Steinfort J, Winkelhoff AJ, Weijden GA. Atmospheric contamination during ultrasonicscaling. J Clin Periodontol. 2004;31(6):458-62. doi:10.1111/j.1600-051X.2004.00511.x

Toroglu MS, Bayramoglu O, Yarkin F, A Tuli. Possibility of Blood and Hepatitis B Contamination Through aerosols generated during debonding procedures. Angle Orthod. 2003;73(5):571-8.

Toroğlu MS, Haytaç MC, Köksal F. Evaluation of aerosol contamination during debonding procedures. Angle Orthod. 2001; 71(4):299-306.doi: 10.1043/00033219(2001)071<0299:EOACDD>2.0.CO;2

Van Strydonck DA, Slot DE, Van der Velden U, Van der Weijden F. Effect of a chlorhexidine mouthrinse on plaque, gingival inflammation and staining in gingivitis patients: a systematic review. J Clin Periodontol. 2012 Nov;39(11):10425516. doi: 10.1111/j.1600-051X.2012.01883.x.

Veena HR, Mahantesha S, Joseph PA, Patil SR, Patil SH. Dissemination of aerosol and splatter during ultrasonicscaling: a pilot study. J Infect Public Health. 2015;8(3):260-5. doi:10.1016/j.jiph.2014.11.004

Villalpando KT, Casarin RC, Pimentel SP, Cirano FR, Casati MZ..A randomized clinical evaluation of triclosan-containing dentifrice and mouthwash association in 
the control of plaque and gingivitis. Quintessence Int. 2010 Nov-Dec;41(10):85561

Walker CB.Microbiological effects of mouthrinses containing antimicrobials. J Clin Periodontol. 1988 Sep;15(8):499-505.

William G. Kohn, Amy S. Collins, Jennifer L. Cleveland, Jennifer A. Harte, Kathy J. Eklund, Dolores M. Malvitz. Guidelines for Infection Control in Dental HealthCare Settings 2003: 1-61.

Weissfeld AS. Infection Control in the Dental Office.CNM 2014.(11):79-84

Word Health Organization. Infection prevention and control measures for acute respiratory infections in healthcare settings. An update; 2007 P:39-47.

Worrall SF, Knibbs PJ, Glenwright HD. Methods of reducing bacterial contamination of the atmosphere arising from use of an air-polisher $\mathrm{Br}$ Dent $\mathrm{J}$. $1987 ; 22 ; 163(4): 118-9$

Yengopal $\mathrm{V}$. The use of essential oil mouthwashes as preprocedural rinses for infection control. SADJ. 2004; 59(6):247-50.

Yates, R., Shearer, B. H., Huntington E, Addy, M. A method to compare four mouthrinses: time to gingivitis level as the primary outcome variable. $\mathrm{J}$ of Clinic Periodontology.2002. 29, 519-23.

Yévenes, Reyes, Campos, Saragoni. The effects of a chlorhexidine rinses on the development of plaque and antibacterial. Av Periodon Implantol 2003;15:19-24

Zemouri C1, de Soet H1, Crielaard W1, Laheij A A scoping review on bioaerosols in healthcare and the dental environment.PLoS One. 2017 May 22;12(5):0178-007. doi: 10.1371/journal.pone.0178007 
